$$
\begin{gathered}
\text { January 2002 } \\
\text { ASOTIN CREEK } \\
\text { INSTREAM HABITAT ALTERATION PROJECTS } \\
\text { HABITAT EVALUATION, ADULT \& JUVENILE HABITAT } \\
\text { UTILIZATION \& WATER TEMPERATURE MONITORING }
\end{gathered}
$$

2001 Progress Report

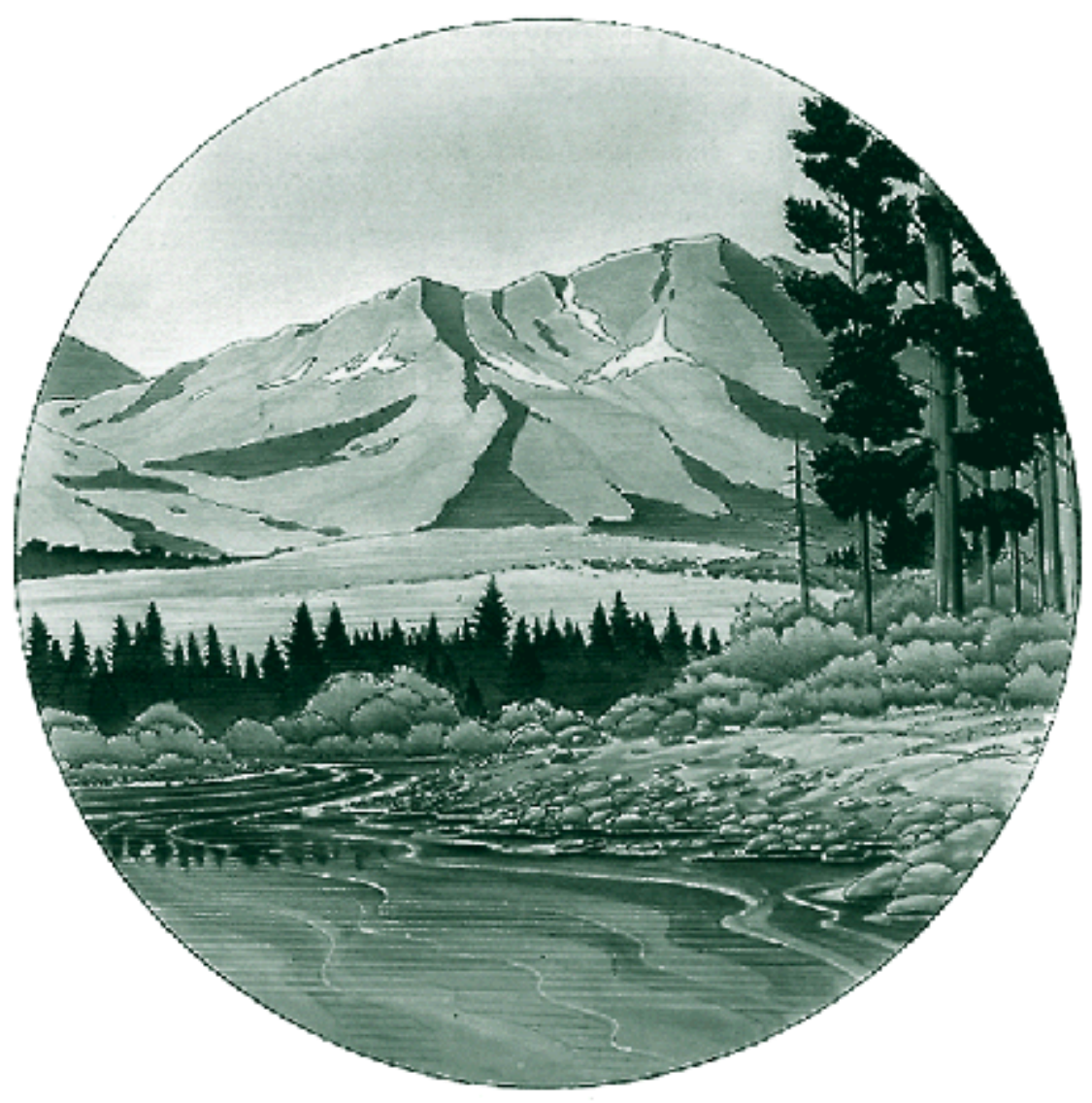

DOE/BP-00006230-1 
This report was funded by the Bonneville Power Administration (BPA), U.S. Department of Energy, as part of BPA's program to protect, mitigate, and enhance fish and wildlife affected by the development and operation of hydroelectric facilities on the Columbia River and its tributaries. The views of this report are the author's and do not necessarily represent the views of BPA.

This document should be cited as follows:

Bumgarner, Joseph D. - Washington Department of Fish \& Wildlife, 2002, Asotin Creek Instream Habitat Alteration

Projects - Habitat Evaluation, Adult \& Juvenile Habitat Utilization \& Water Temperature Monitoring, 2001 Progress

Report, Report to Bonneville Power Administration, Contract No. 00006230, Project No. 199905400, 41 electronic

pages (BPA Report DOE/BP-00006230-1)

This report and other BPA Fish and Wildlife Publications are available on the Internet at:

\section{http://www.efw.bpa.gov/cgi-bin/efw/FW/publications.cgi}

For other information on electronic documents or other printed media, contact or write to:

Bonneville Power Administration

Environment, Fish and Wildlife Division

P.O. Box 3621

905 N.E. 11 th Avenue

Portland, OR 97208-3621

Please include title, author, and DOE/BP number in the request. 


\title{
Asotin Creek \\ Instream Habitat Alteration Projects \\ Habitat Evaluation, Adult and Juvenile Habitat Utilization and Water Temperature Monitoring \\ 2001 Progress Report
}

\author{
by \\ Joseph D. Bumgarner \\ Washington Department of Fish and Wildlife \\ Fish Program/Science Division \\ Snake River Lab \\ 401 S. Cottonwood \\ Dayton, Washington 99328
}

to

Asotin County Conservation District

720 Sixth Street, Suite B

Clarkston, Washington 99403

January 2002 


\section{Acknowledgments}

I thank the Asotin County Conservation District (ACCD) and the Conservation District Board of Supervisors for funding this evaluation work. Brad Johnson, (ACCD) manager, was instrumental in supporting these activities and provided rough site maps and accompanied WDFW on an on-site visit to the habitat sites. Brad also provided descriptions of proposed instream structures and their intended function at each site.

I thank all of the Asotin County landowners for their participation in stream restoration efforts. Without their cooperation this project would not have been possible.

I thank the entire field crew of the Snake River Lab, and in particular our temporary technicians Aulin Smith, and Chris Fulton who entered and verified all the data collected and presented in this report. I thank Brad Johnson, Mark Schuck, and Mike Gallinat for reviewing and providing useful comments to earlier drafts of this report. 


\section{Table of Contents}

List of Tables__ ii

List of Figures__ iiiii

List of Appendices__ iiv

Introduction___ 1

Methods__ 3

Site Locations __ 3

Materials__ 3

Habitat Measurements __ 3

Snorkeling _ 5

Adult Utilization - Redd Surveys __ 6

Temperature Monitoring__ 7

Results__ 8

Post-construction Habitat Measurements from 1999 Projects____ 8

Pre-Construction Habitat Measurements from 2001 Projects ___ 10

Charley Creek__ 11

Mainstem Asotin Creek__ 11

George Creek _ـ 12

Snorkeling _ 14

Habitat Alteration Sites__ 16

Adult Utilization - Redd Surveys ___ 18

Temperature Monitoring___ 18

Discussion__ 21

Habitat Surveys __ 21

Fish Utilization - Snorkeling and Redd Counts ___ 22

Temperature __ 22

References__ 24

Appendix $A \longrightarrow 25$

Appendix $B$ 


\section{List of Tables}

Table 1. Pool quality ratings for streams between 20 and 60 feet in width (from Platts et al. 1983).

Table 2. Summary of 1999 project sites in Mainstem Asotin Creek surveyed in 1999 and 2001. 9

Table 3. Pool classifications at three mainstem Asotin Creek sites in 1999 and 2001.

Table 4. Summary of pre-construction habitat measurements in three Charley Creek sites, and two mainstem Asotin Creek sites in 2001.

Table 5. Pool classifications at pre-construction in three Charley Creek sites, two mainstem Asotin Creek sites, and one George Creek site in 2001.

Table 6. Site location and the greatest daily mean and maximum water temperatures by month at various locations in the Asotin Creek Watershed, 2000 and 2001. 


\section{List of Figures}

Figure 1. Visual representation of snorkel surveys conducted showing approximate areas snorkeled within index (control) and habitat altered (treatment) sites.

Figure 2. Large Organic Debris (LOD) placements along an eroding bank at Thiessen \#5b._ 10

Figure 3. Photo of eroding bank along existing road along Charley Creek. 11

Figure 4. Proposed channel reconstruction at the Hendrickson project site. 12

Figure 5. George Creek project site. 13

Figure 6. Age 0 juvenile steelhead densities at index sites in mainstem Asotin Creek, 2001. 15

Figure 7. Age 1+ juvenile steelhead densities at index sites in mainstem Asotin Creek, 2001. 16

Figure 8. Mean densities of Age 0 and Age 1+ juvenile steelhead at habitat alteration and index sites in mainstem Asotin Creek in 1999, 2000, and 2001.

Figure 9. Mean densities of Age 0 and Age 1+ juvenile steelhead in three habitat structure types within habitat alteration and index sites in mainstem Asotin Creek, summers of 1999, 2000, and 2001. 18

Figure 10. Map of Asotin Creek Watershed and locations of water temperature monitors deployed by WDFW and USFS in 2001. 


\section{List of Appendices}

Appendix A: Juvenile summer steelhead densities from snorkel surveys at index and habitat sites in 2001

Appendix A: Table 1. List of index snorkel sites, and juvenile steelhead densities (fish $/ 100 \mathrm{~m}^{2}$ ) in mainstem Asotin Creek, September 2001.

Appendix A: Table 2. List of habitat alteration sites, and juvenile steelhead densities (fish $/ 100 \mathrm{~m}^{2}$ ) in mainstem Asotin Creek, September 2001.

Appendix B: Average, minimum and maximum water temperatures collected in Mainstem Asotin Creek, North and South Forks of Asotin Creek, and Charley Creek in 2001.

Appendix B: Figure 1. Average, minimum, and maximum water temperature in mainstem Asotin Creek at river kilometer 0.3 in 2001, Asotin City Park.

Appendix B: Figure 2. Average, minimum, and maximum water temperature in mainstem Asotin Creek at river kilometer 4.3 in 2001, above where the mouth of George Creek enters the river.

Appendix B: Figure 3. Average, minimum, and maximum water temperature in mainstem Asotin Creek at river kilometer 11.4 in 2001, Headgate County Park.

Appendix B: Figure 4. Average, minimum, and maximum water temperature in mainstem Asotin Creek at river kilometer 19.5 in 2001, bridge crossing at confluence of the North and South Forks.

Appendix B: Figure 5. Average, minimum, and maximum water temperature in North Fork Asotin Creek at river kilometer 11.8 in 2001 (U. S. Forest Service boundary fence line).

Appendix B: Figure 6. Average, minimum, and maximum water temperature in South Fork Asotin Creek at river kilometer 0.1 in 2001 (near the mouth of the South Fork). 31

Appendix B: Figure 7. Average, minimum, and maximum water temperature in Charley Creek at river kilometer 0.2 in 2001 (near the mouth of Charley Creek).

Appendix B: Figure 8. Average, minimum, and maximum water temperature in Charley Creek at river kilometer 8.5 in 2001 (at the boundary fenceline for State land property). 


\section{Introduction}

Asotin Creek originates from a network of deeply incised streams on the slopes of the Blue Mountains of southeastern Washington. The watershed drains an area of 322 square miles that provides a mean annual flow of $74 \mathrm{cfs}$. The geomorphology of the watershed exerts a strong influence on biologic conditions for fish within the stream. Historic and contemporary land-use practices have had a profound impact on the kind, abundance, and distribution of anadromous salmonids in the watershed. Fish habitat in Asotin Creek and other local streams has been affected by agricultural development, grazing, tilling practices, logging, recreational activities and implementation of flood control structures (Neilson 1950).

Historically, the basin produced anadromous fish runs of both spring chinook salmon (Oncorhychus tshawytscha) and summer steelhead (O. mykiss), and a resident population of bull trout (Salvelinus confluentus), and remain the species of concern. Each of these species are all below historical levels and are currently listed as "threatened" under the Endangered Species Act. Limited documentation of the wild spring chinook run-strength is available. For example, in 1934, 25 adults were rescued from the creek below Headgate Dam to prevent them from perishing; thereafter, the spring chinook population continued to decline because of continued poor access to the upper stream, habitat degradation and other factors (Parkhurst 1950). Washington Department of Fish and Wildlife personnel documented spring chinook spawning and smolt emigration through the 1980s but no significant spawning has been documented since 1985. The species is considered extirpated in the basin (Bumgarner et al. 1998). Endemic steelhead persist throughout much of the basin, but the population is considered depressed (WDF and WDW 1993). The average run of summer steelhead into portions of Asotin Creek (North Fork, South Fork, Charley Fork and the mainstem) has been about 400 spawning fish since 1986 (Mark Schuck personnel communication). Bull trout within the basin are also considered depressed, and limited data are available on their status.

The Asotin Creek Model Watershed Master Plan was completed in 1994. The plan was developed by a landowner steering committee for the Asotin County Conservation District (ACCD), with technical support from various Federal, State and local entities. Actions identified within the plan to improve the Asotin Creek ecosystem fall into four main categories: 1) Stream and Riparian, 2) Forestland, 3) Rangeland, and 4) Cropland. Specific actions to be carried out within the stream and in the riparian area to improve fish habitat were: 1) create more pools, 2) increase the amount of large organic debris (LOD), 3) increase the riparian buffer zone through tree planting, and 4) increase fencing to limit livestock access.

All of these actions, in combination with other activities identified in the Plan, are intended to stabilize the river channel, reduce sediment input, increase the amount of available fish habitat (adult and juvenile) and protect private property. Evaluation work described within this report was to document the success or failure of the program regarding the first two items listed (increasing pools and LOD).

Beginning in 1996, the ACCD, with cooperation from local landowners and funding from Bonneville Power Administration began constructing instream projects to improve fish habitat. 
In 1998, the ACCD identified the need for a more detailed analysis of these instream projects to fully evaluate their effectiveness at improving fish habitat. Therefore, ACCD contracted with WDFW's Snake River Lab (SRL) to take pre- and post-construction measurements of the habitat (i.e., pools, LOD, width, depth) at each site, and to evaluate fish use within some of the altered sites. These results have been published annually as progress reports to the ACCD (Bumgarner et al. 1999, Wargo et al. 2000, and Bumgarner and Schuck 2001).

The ACCD also contracted with the WDFW SRL to conduct other evaluation and monitoring in the stream such as: 1) conduct snorkel surveys at habitat alteration sites to document fish usage following construction, 2) deploy temperature monitors throughout the basin to document summer water temperatures, and 3) attempt to document adult fish utilization by documenting the number of steelhead redds associated with habitat altered areas.

This report provides a summary of pre-construction measurements taken on three proposed Charley Creek habitat sites during 2001, two sites in main Asotin Creek, and one site in George Creek, a tributary that enters in the lower Asotin Creek basin. Further, it provides a comparison of measurements taken pre- and post-construction on three 1999 habitat sites taken two years later, but at similar river flows. It also presents data collected from snorkel surveys, redd counts, and temperature monitoring. 


\section{Methods}

\section{Site Locations}

Local landowners and ACCD personnel selected project locations with input and approval from WDFW fish and habitat biologists (Hydraulic Permits). Rough maps and printed preconstruction photographs of each site were supplied to the SRL in 1998 and 1999. In 2001, preconstruction site visits were conducted by ACCD and SRL to discuss appropriate evaluation techniques. Before habitat measurements were collected at new sites in 2001, SRL biologists established upper and lower site boundaries that encompassed proposed construction areas. At each site the upper and lower boundary was marked with flagging, and a tree was painted. The purpose of the flagging and the marked tree was to ensure that pre- and post-construction habitat measurements would be collected from identical river locations following construction activities. Similar techniques have been used in the past, but at several sites flagging was moved or lost during construction activities. For the planned re-evaluation of 1998 and 1999 sites, every effort was made to re-locate upper boundaries as close as possible to 1998 or 1999 pre-construction locations. The upper and lower ends of each site were then re-marked for additional evaluations in the coming years.

\section{Materials}

Two $2 \mathrm{~m}$ measuring rods (marked every $0.05 \mathrm{~m}$ ), one $30 \mathrm{~m}$ measuring tape (marked every 0.01 $\mathrm{m})$, one 5-gallon bucket, fluorescent dye, a stopwatch, and data forms.

\section{Habitat Measurements}

Habitat measurements were conducted so that the following could be derived from the data: 1) Site length, 2) mean site depth, 3) mean wetted width, 4) mean and standard deviation (SD) of thalweg depth, 5) Quantitative and qualitative counts of woody debris, 6) pool number and quality, 7) pool depth, area, and volume, and 8) water velocity using a dye rate (water transit time through the site divided by site length in meters, as measured by movement of fluorescent dye).

From the top of each site, channel wetted width and water depths were measured along transects at $10 \mathrm{~m}$ intervals or less, depending upon the overall site length. For sites less than $100 \mathrm{~m}$ in length, we divided the site by 10 to calculate the interval needed. At each transect, two people on opposite stream banks held a measuring tape perpendicular to stream flow. Width was measured from wetted edge to wetted edge. With the tape held in place, a third person measured depths to the nearest centimeter at $1 \mathrm{~m}$ intervals across the stream (smaller streams such as Charley Creek were measured every 0.5 meters). Surveyors then measured the appropriate distance downstream and repeated the cross-stream measurements. This process was repeated to the bottom of each site. If the stream channel split, the width and depth measurements were made as described above, but islands were recorded as "dry". Each measurement recorded as "dry" was later subtracted from the total transect width, yielding the total wetted width. 
Large Organic Debris (LOD) was measured if it: 1) touched or was within $30 \mathrm{~cm}$ of the water surface, 2) was greater than 15 centimeters in width, and 3) was stationary (held firmly in place). Sections or pieces of LOD that extended outside the wetted stream area were not included in the measurements.

Pools were measured if: 1) they were greater than $30 \mathrm{~cm} \times 30 \mathrm{~cm}$ in surface area, and 2) had a minimum depth of $15 \mathrm{~cm}$. Pools were measured for length, width, average depth, a maximum depth, and were assigned a pool rating (Table 1).

Table 1. Pool quality ratings for streams between 20 and 60 feet in width (from Platts et al. 1983).

\begin{tabular}{|c|c|c|}
\hline Key & Description & Pool Rating \\
\hline $\begin{array}{l}1 \mathrm{~A} \\
1 \mathrm{~B} \\
1 \mathrm{C} \\
2 \mathrm{~A} \\
2 \mathrm{~B} \\
3 \mathrm{~A} \\
3 \mathrm{~B} \\
4 \mathrm{~A} \\
4 \mathrm{~B} \\
4 \mathrm{C} \\
5 \mathrm{~A} \\
5 \mathrm{~B}\end{array}$ & $\begin{array}{l}\text { If the maximum pool diameter (length or width) is within } 10 \% \text { of the mean stream width of study site. } \\
\text { If the maximum pool diameter (length or width) exceeds the mean stream width of study site by } 10 \% \text {. } \\
\text { If the maximum pool diameter (length or width) is less than the mean stream width of study site by } 10 \% \text {. } \\
\text { If the pool is less than } 0.6 \mathrm{~m}(2 \mathrm{ft}) \text { in maximum depth. } \\
\text { If the pool is more than } 0.6 \mathrm{~m}(2 \mathrm{ft}) \text { in maximum depth. } \\
\text { If the pool is over } 0.9 \mathrm{~m}(3 \mathrm{ft}) \text { in max. depth, or if pool is over } 0.6 \mathrm{~m} \text { in depth and has abundant fish cover }{ }^{1} \\
\text { If the pool is less than } 0.6 \mathrm{~m} \text { in max. depth, or if pool is } 0.6-0.9 \mathrm{~m} \text { in max. depth and the pool lacks fish cover } \\
\text { If the pool is over } 0.6 \mathrm{~m} \text { in max. depth with intermediate }{ }^{2} \text { or better cover } \\
\text { If the pool is less than } 0.6 \mathrm{~m} \text { in max. depth but pool cover for fish is intermediate or better } \\
\text { If the pool is less than } 0.6 \mathrm{~m} \text { in max. depth and pool cover is classified as exposed }{ }^{3} \\
\text { If the pool has intermediate to abundant cover } \\
\text { If the pool has exposed cover conditions }\end{array}$ & $\begin{array}{l}\text { Go to } 2 \mathrm{~A}, 2 \mathrm{~B} \\
\text { Go to } 3 \mathrm{~A}, 3 \mathrm{~B} \\
\text { Go to } 4 \mathrm{~A}, 4 \mathrm{~B}, 4 \mathrm{C} \\
\text { Go to } 5 \mathrm{~A}, 5 \mathrm{~B} \\
\text { Go to } 3 \mathrm{~A}, 3 \mathrm{~B} \\
\text { Rate } 5 \\
\text { Rate } 4 \\
\text { Rate } 3 \\
\text { Rate } 2 \\
\text { Rate } 1 \\
\text { Rate } 3 \\
\text { Rate } 2\end{array}$ \\
\hline
\end{tabular}

The thalweg (generally the point of greatest current velocity and depth) was measured starting from the bottom of each site and taking a measurement every 1-2 meters as the surveyor moved upstream through the site. The thalweg measurement in split channels was taken in the channel with the largest volume of water.

As habitat alterations are completed, channel width and depth may change in portions of each site. Also, river flow will deflect off objects placed within the stream, altering river shape and increasing site complexity. These changes may, in turn, affect water velocity (meters/second) within the site. For a rough estimate of water velocity through the site, the rate at which a fluorescent dye traveled down the thalweg from upper to lower end of the site (water velocity) was determined. The dye was mixed in a five gallon bucket of water, and then quickly poured from the bucket into the thalweg. The dye was timed to a point when the dye in the water reached a consistent dark intensity at the lower end of the site. This generally occurred 10-20 seconds after the first traces of dyed water reached the lower end.

Data were entered into the computer and summarized to describe site characteristics. Wetted surface area and volume, and wetted width-to-depth ratios were calculated from transects. The standard deviation (SD) of thalweg depth was calculated to represent the depth complexity of a site. To further describe habitat complexity, the amount of LOD was reported as a percentage of the site's wetted surface area and pool volume was reported as a percentage of the site's volume. 
An average pool rating for each site was also calculated to indicate the most common type of pool present within each site.

\section{Snorkeling}

To evaluate fish use of habitat altered areas, snorkel surveys (Griffith 1981, Schill and Griffith 1984) were conducted. While many fish species are present in Asotin Creek, only juvenile summer steelhead were counted during snorkel surveys, as they are one of the primary species of concern within the basin. Other ESA listed species are present in the Asotin Creek basin, but their low numbers and rare appearance within sites that can be effectively snorkeled lessened their value for this evaluation. Juvenile steelhead in mainstem Asotin Creek range from 0-2 years in age (Schuck et al. 1997) and are found in most areas of the creek, with the youngest fish holding along the stream bank. Surveys from 1999 to 2001 have been conducted in late August or early September.

In addition to snorkeling habitat altered areas, SRL biologist established 14 index (control) sites in 1999 to compare with the number of juvenile steelhead counted within altered areas, and for long term monitoring of stream populations. Index sites were established every 1.5-2.0 river kilometers (Rk) between the Asotin City Park (Rk 0.5) and the North and South Fork confluence bridge (Rk 23). No index sites were established in the South Fork or Charley Creek because they are too shallow for effective snorkel surveys. Neither were index sites were established in the North Fork, as Age 0 juvenile steelhead usually have not grown large enough to leave the shallow, protective habitat along the stream bank by our survey time, and therefore cannot be effectively counted by snorkeling.

Length, and three to five width measurements were collected from habitat altered or index snorkel sites to standardize the fish counts into fish densities (fish/100 $\mathrm{m}^{2}$ ). The length of each snorkel site was generally measured before snorkeling so that an upper and lower end of the site would be known to each snorkeler. However, if measuring the site meant walking through the site and perhaps displacing fish, the snorkelers would pick a landmark (rock, tree) for the upper end of the site, and measure the site after snorkeling was completed. Two biologists snorkeled the site at the same time swimming upstream (Figure 1), each taking approximately one-half of the creek's width. Snorkelers communicated visually about who would count the fish in the middle of stream when the snorkelers would meet.

Proposed site lengths at index (control) sites were 40 meters. This length was considered adequate to represent the general habitat available to fish in the creek, and would generally include a representation of riffles, runs and pools present in the stream. Snorkel site lengths at habitat alteration sites were typically shorter, as the purpose of the area snorkeled was document fish density and usage within the hydraulic control of the instream structures. While entire habitat sites could have been snorkeled, it would have eliminated our ability to examine fish usage and densities at a variety of structures. 


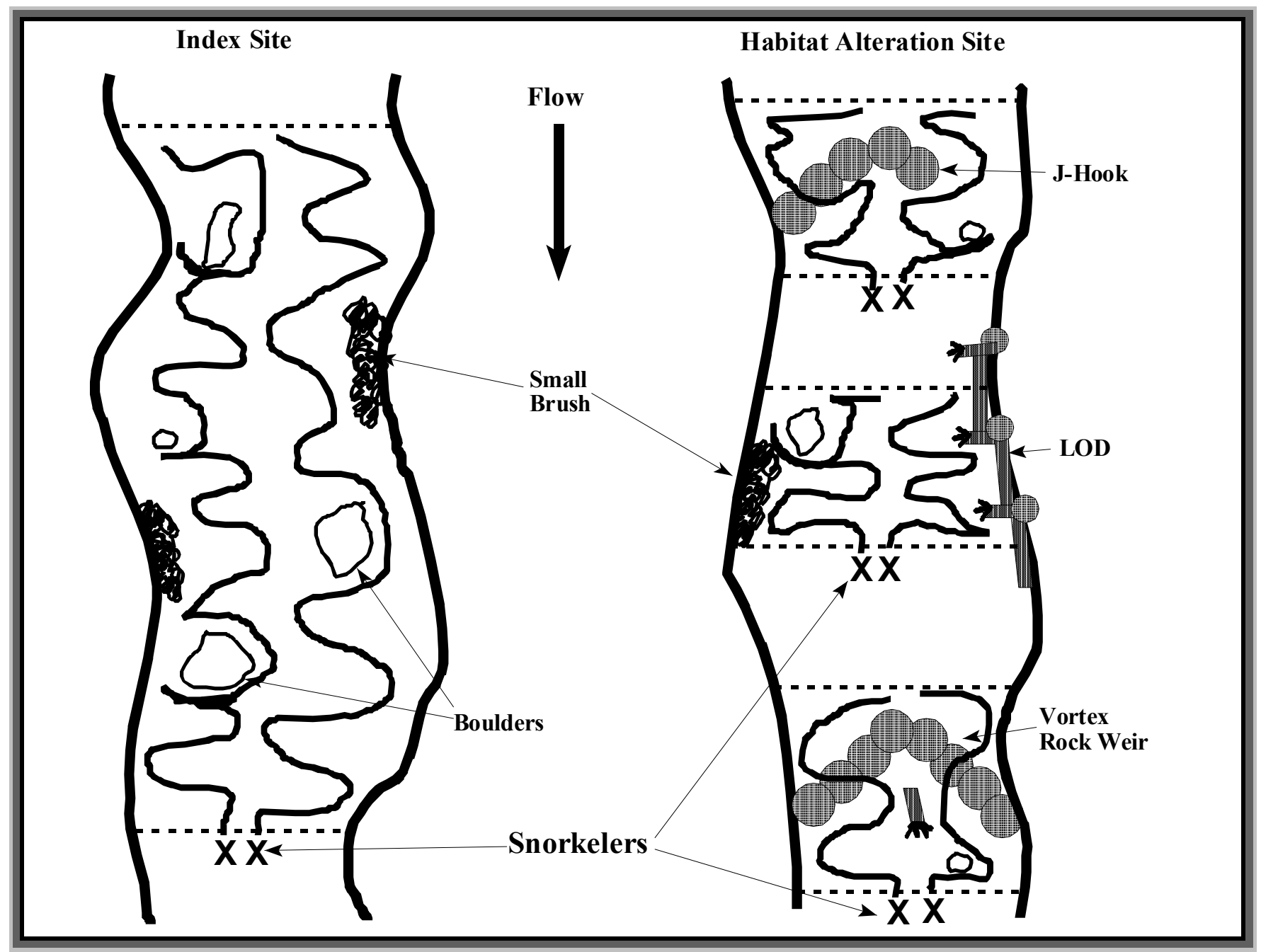

Figure 1. Visual representation of snorkel surveys conducted showing approximate areas snorkeled within index (control) and habitat altered (treatment) sites.

Snorkel data were entered into a spreadsheet and densities were calculated for Age 0 and Age 1+ juvenile steelhead for each site. Densities between treatment and control sites were then compared for each age group. We performed Student $t$-test, One-way Analysis of Variance (ANOVA), and Tukey tests (Zar 1984) to determine if there were significant differences between mean fish densities in treatment and control sites, and among various habitat alteration types.

\section{Adult Utilization - Redd Surveys}

Spawning ground surveys have been conducted on an annual basis to document the distribution of redds in the river, and to estimate the number of fish returning to the system. WDFW-SRL staff conducted weekly spawning ground surveys in index sections of mainstem Asotin Creek in March and April, 2001. Index sections were as follows: 1) the confluence bridge (near the North and South Fork) downstream 2.6 road miles (4.3 river kilometers), 2) and 4 road miles (6.6 river kilometers) around Headgate Park (3.3 Rk upstream and 3.3 Rk downstream). 
During 2001 redd surveys, crews made note of redd location in association with the artificial instream structures that have been added in Asotin Creek since 1996. Redds were considered to be associated if they were within the hydraulic control of a treatment structure. Hydraulic control was defined as any location in the vicinity of a treatment structure in which the velocity, depth, or spawning gravels were potentially controlled, or influenced by the habitat structure.

\section{Temperature Monitoring}

To document stream temperatures, SRL deployed data loggers (Onset Corporation: Optic StowAway $\left.{ }^{\circledR}\right)$ at various locations throughout the Asotin Creek watershed. Temperature data were exported into Quattro Pro (C) spreadsheets. Daily minimum, maximum and mean temperatures were calculated using a Quattro Pro spreadsheet macro. 


\section{Results}

Site complexity as defined for this report indicates the amount of habitat variation in the site (e.g. riffles, runs, pools, LOD, boulders, surface turbulence, etc.). The greater the site complexity, the greater the likelihood that juvenile and adult salmonids, and other fish species would utilize that space compared to a uniform, barren site (Everest 1986). A large thalweg SD indicates more depth variation (i.e. riffles, pools and runs), whereas a small thalweg SD indicates less depth variation (e.g. stream site may be all a shallow riffle). The larger the percentage of either LOD or pools (compared to site area or volume), the greater the potential site complexity.

One problem in the past with the instream habitat evaluations has been trying to complete the surveys during similar flow conditions year-to-year. From 1998-2000, SRL had relied on the USGS station in lower Asotin Creek. However, flow data were unavailable until after the measurements and work are completed. As a result, while surveys were completed at similar times of the summer, flow varied greatly in all three years (Bumgarner and Schuck 2001). For the 2001 surveys, SRL used a Swoffer Instruments velocity meter to calculate flows. Many trips were made to Asotin Creek to take flows so that our 1999 site post-construction measurements would be conducted under similar flow conditions. We had intended to collect post-construction measurements from all sites in Asotin Creek completed in 1998 and 1999. However, an extreme low water year in 2001 prevented us from completing the sites done in 1998, only the 1999 sites were completed.

\section{Post-construction Habitat Measurements from 1999 Projects}

Four sites on mainstem Asotin Creek were selected for habitat improvements in 1999, yet only three were finished. Of those, site Koch \#2, was begun in 1998 and the additional work completed in 1999 was not considered significant enough to warrant the pre or post-construction measurements. Sites re-measured in 2001 were Thiessen 5 (5a and 5b), and Jungert. Stream flows between the 1999 and 2001 were similar (Table 2), and visual changes within each site were evident. Further, by examining the data collected for LOD, pools, and SD thalweg depth, we can demonstrate that habitat alterations (increased complexity) did occur within these sites. 
Table 2. Summary of 1999 project sites in Mainstem Asotin Creek surveyed in 1999 and 2001.

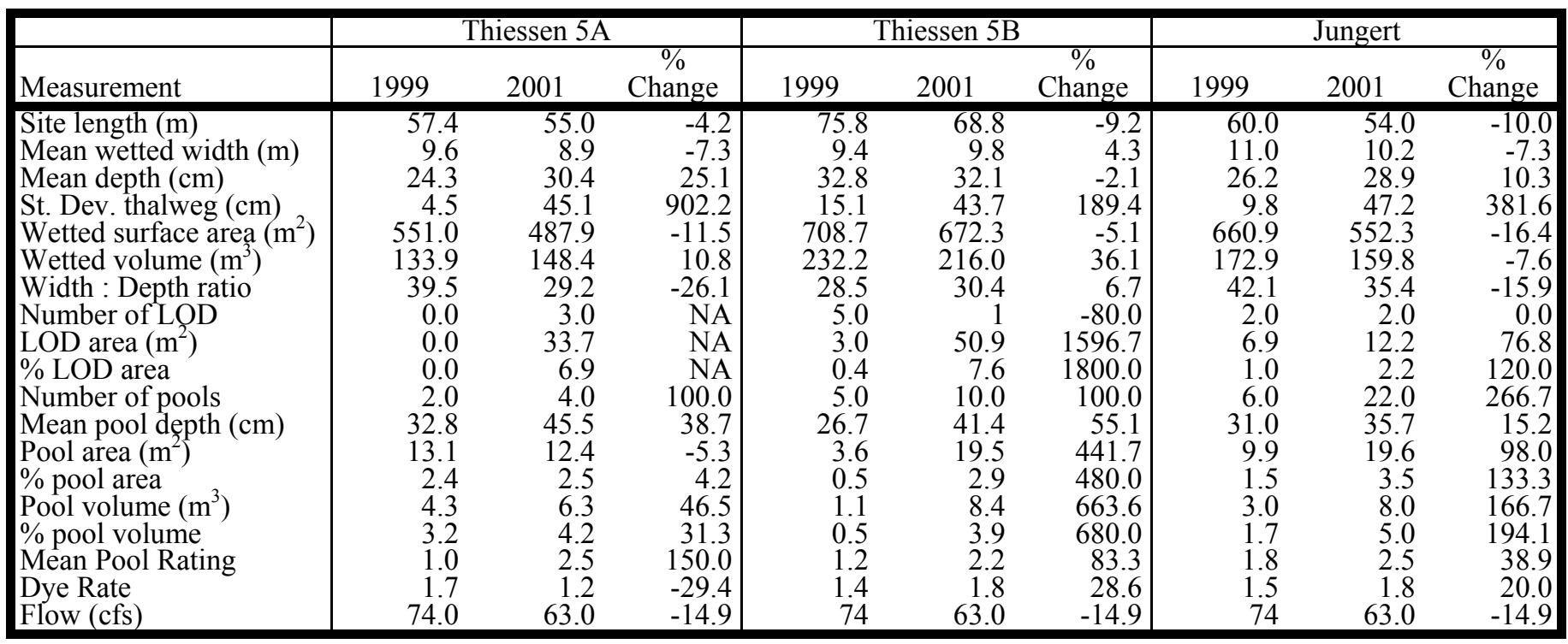

At the Thiessen site, SRL staff split the site into two sections due to the overall length and distance between habitat structures. We felt that evaluating two smaller sites would provide greater sensitivity of the data (see discussion in Wargo et al. 2000). The project intent for Thiessen 5A and 5B was to install LOD (with rootwad ends attached) to prevent further erosion of stream banks, yet provide woody material and complexity for fish habitat. One eroding bank was located against a cattle grazing field, with loss of pasture and some riparian habitat should the bank continue to erode. The other eroding bank was located near the Asotin Creek road, and continued erosion could threaten road integrity. At Thiessen 5A, the SD of thalweg increased by over $900 \%$, indicating a greater complexity of the river channel. Also, the area of LOD within the site went from zero in 1999 to $6.9 \%$ in 2001 (Table 2). The number of pools increased, as did the mean pool rating and depth of pools. At Thiessen 5B, the SD of thalweg depth increased by nearly $200 \%$. This was likely a result of the construction and placement of the LOD within the site (Figure 2), which over time has allowed certain sections located near the LOD to scour and form deeper pools in the thalweg. The area of LOD within the site increased from $0.4 \%$ in 1999 to $7.6 \%$ in 2001 (Table 2), an increase of over 1,800\%. The number of pools, area, volume, and overall pool rating greatly increased at this site. For both Thiessen 5A and 5B, Class 1 and 2 pools dominated the site prior to construction. Following the work, nearly all the pools rated as Class 2 or Class 3 (Table 3).

Table 3. Pool classifications at three mainstem Asotin Creek sites in 1999 and 2001.

\begin{tabular}{|c|c|c|c|c|c|c|c|c|c|c|}
\hline & \multicolumn{5}{|c|}{1999 Pool Classifications } & \multicolumn{5}{|c|}{2001 Pool Classifications } \\
\hline Site Name & 1 & 2 & 3 & 4 & 5 & 1 & 2 & 3 & 4 & 5 \\
\hline Thiessen 5A & 2 & 0 & 0 & 0 & 0 & 0 & 2 & 2 & 0 & 0 \\
\hline Thiessen 5B & 4 & 1 & 0 & 0 & 0 & 1 & 6 & 3 & 0 & 0 \\
\hline Jungert 6 & 1 & 5 & 0 & 0 & 0 & 0 & 12 & 10 & 0 & 0 \\
\hline Total & 7 & 6 & 0 & 0 & 0 & 1 & 20 & 15 & 0 & 0 \\
\hline Percent & 53.8 & 46.2 & 0 & 0 & 0 & 2.8 & 55.6 & 41.6 & 0.0 & 0.0 \\
\hline
\end{tabular}


Prior to construction at the Jungert site, there were old cars in the creek or very close to the creek. Asotin County Emergency Service received a grant from Department of Ecology to remove the vehicles. However, a condition of the removal was for improved stream bank protection and fish habitat. Managers agreed that four J-Hooks rock structures would be placed in the stream to provide the bank protection (redirect stream flow to opposite channel), yet create pools for fish habitat (either juvenile rearing or adult holding). The vehicles were removed from the site, and the J-Hooks were added which greatly increased the number of Class 2 and 3 pools within the site (Table 3). Further, variation as determined by thalweg depth, and the overall percent area or volume of pools between years increased dramatically.

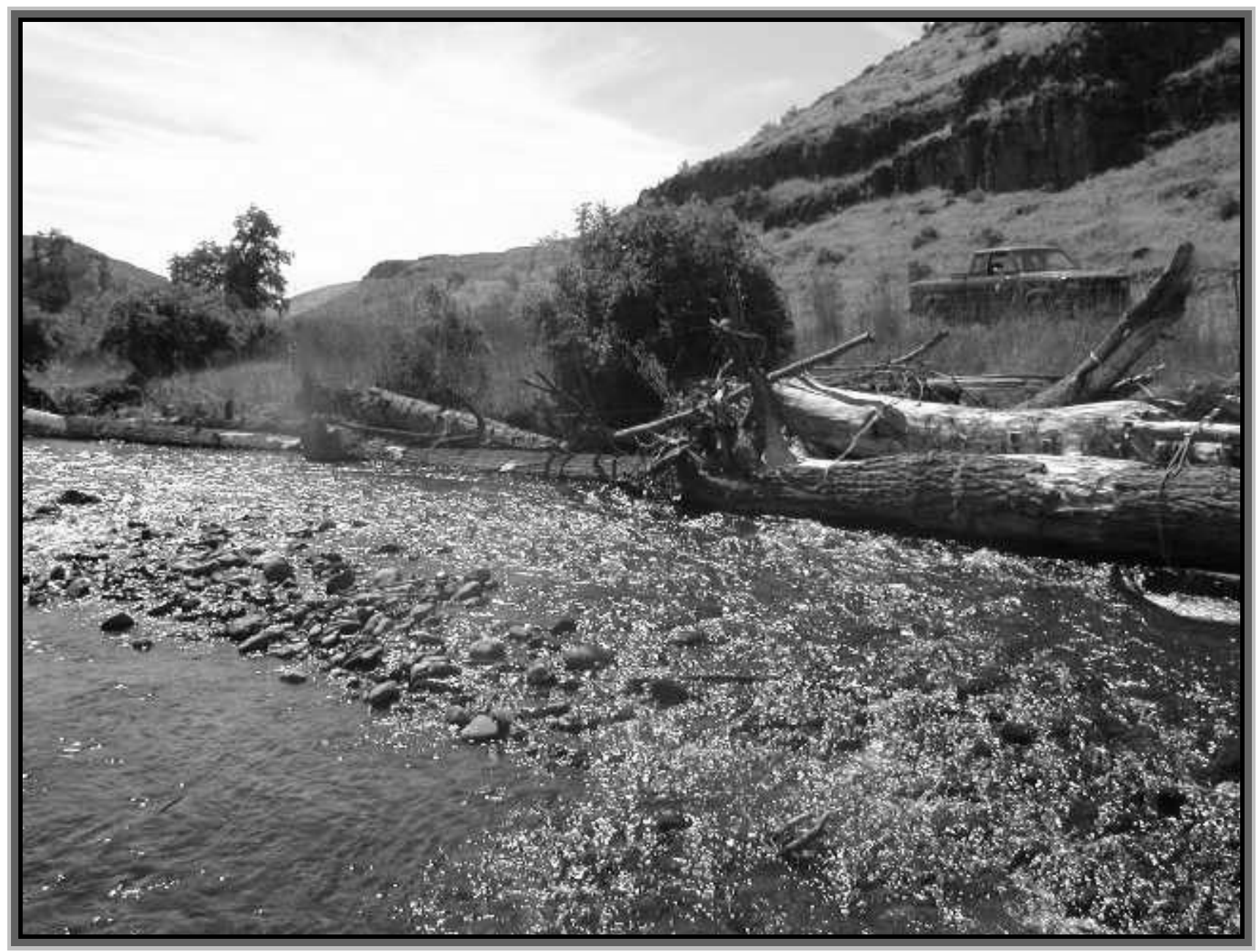

Figure 2. Large Organic Debris (LOD) placements along an eroding bank at Thiessen $\# 5$ b.

\section{Pre-Construction Habitat Measurements from 2001 Projects}

Six project sites were originally identified for habitat alterations in 2001. Three of the sites were located in Charley Creek (2000 projects identified but not completed), two sites were in the mainstem Asotin Creek, and one site was located in George Creek. Pre-construction measurements were completed on 5 June for the Charley Creek and mainstem Asotin Creek 
sites. The George Creek project site survey was not completed until 3 July. Stream flows were taken at each project for future evaluations.

The intent for each of the project sites is as follows:

\section{Charley Creek}

Charley Creek \#'s1-3, 2001: A private road, which lies along Charley Creek, is used by the landowner for access to his cattle grazing operation. Also, cattle graze on the road and in the creek adjacent to the road. This primitive road is being eroded away by Charley Creek in many locations, and has partially washed out an existing fence at one site (Figure 3). The landowner indicated that in the interest of stream restoration, he would be willing to fence off these areas from cattle grazing. However, fencing off the stream would be useless unless the eroding stream bank could be stabilized. ACCD proposed to place fish habitat structures (rock J-Hooks and rootwad revetments) to stabilize the bank. This would also provide increased LOD and pool area within the site that are currently lacking. Each site will also be planted with native woody and herbaceous species.

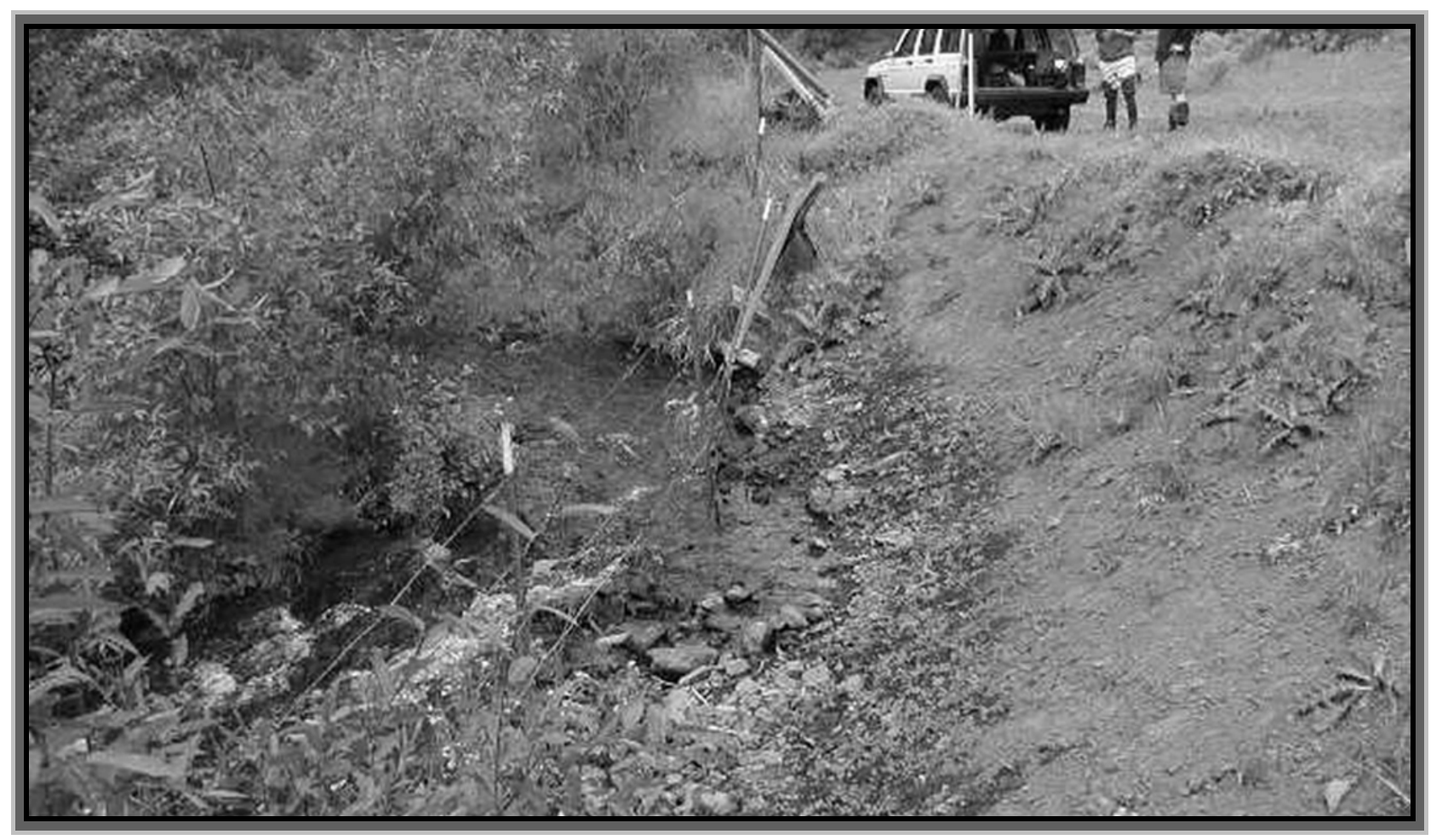

Figure 3. Photo of eroding bank along existing road along Charley Creek.

\section{Mainstem Asotin Creek}

Thiessen \#1-01:

This project site currently has very little instream structure, little woody debris, and the banks have been cut very low due to grazing practices. The stream has cut into existing pastureland in 
these low spots. The purpose of the project will be to re-enforce the low slope banks from additional erosion, and to add other instream structures to diversify the instream channel. Grazing along this section of river will be altered to promote a more continuous riparian area, and to decrease the erosion problem.

Hendrickson \#1-01: The creek within this project site was pushed back along side a rock cliff following floods in 1996 and 1997, and was straightened for about 200 meters (Figure 4). The current flood channel is very narrow, and will likely expand should a flood event occur. Further, complex structure within this section is currently lacking due to confinement of the river channel. The purpose of this project will be to increase the stream length by creating more of a meander pattern within the existing river channel. Estimated stream length may increase by as much as $25 \%$ once completed. Instream structures will increase pools and woody debris for fish habitat. Further, the landowner has agreed to eliminate all grazing from this section of the creek so that the riparian corridor can be enhanced, and erosion of the stream bank will be reduced.

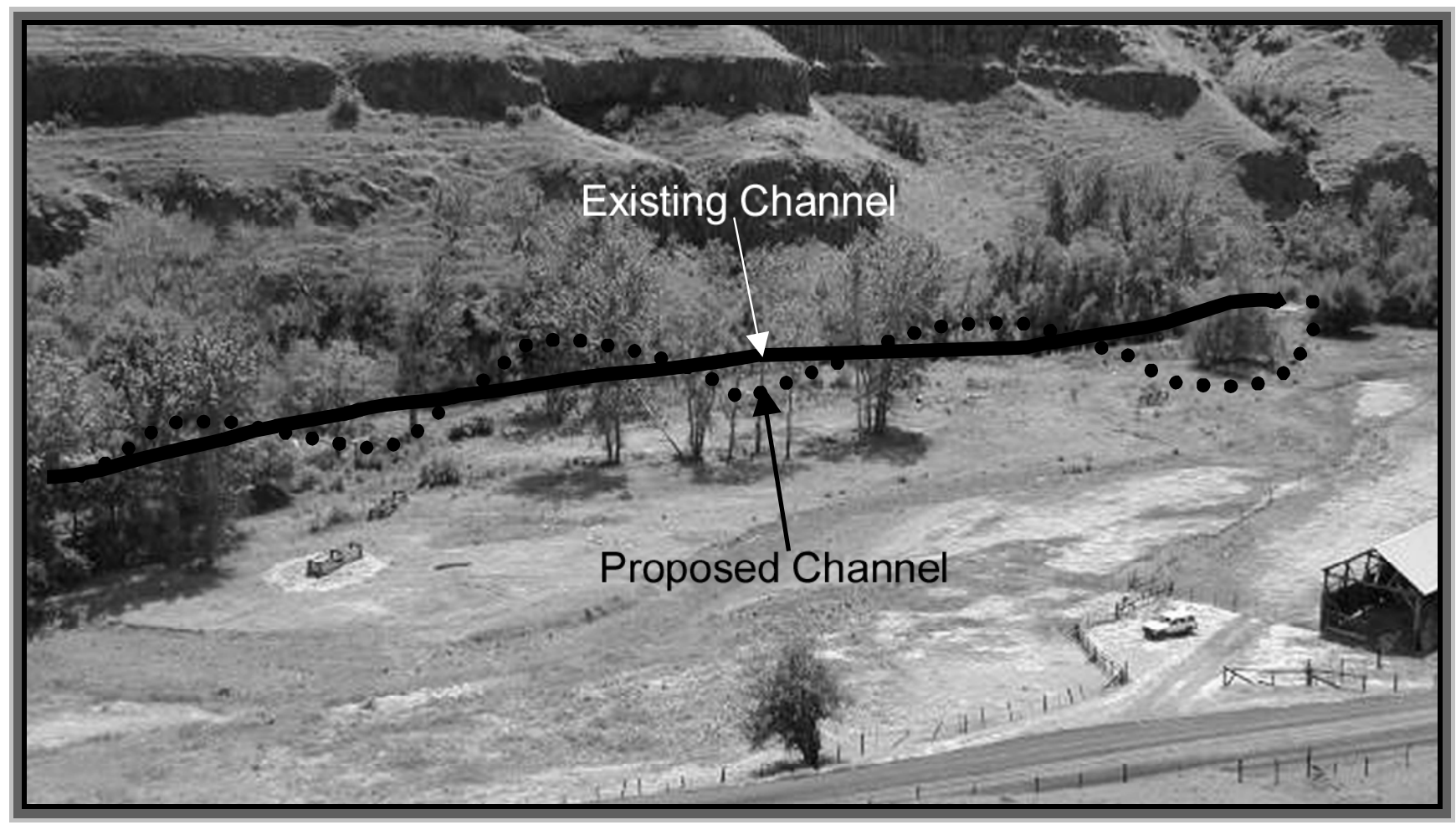

Figure 4. Proposed channel reconstruction at the Hendrickson project site.

\section{George Creek}

George Creek \#1-01: This section of George Creek was completely blown out by previous floods. No riparian vegetation remains and numerous large gravel bars create conditions that during summer flows causes the creek to go sub-surface (Figure 5). The purpose of this project is to re-establish the stream channel to maintain surface flow, increase the stream channel length by constructing a meander pattern, and to add complex fish habitat to provide pools and large 
woody debris. Native species vegetation will be planted to enhance the stream corridor with riparian shade.

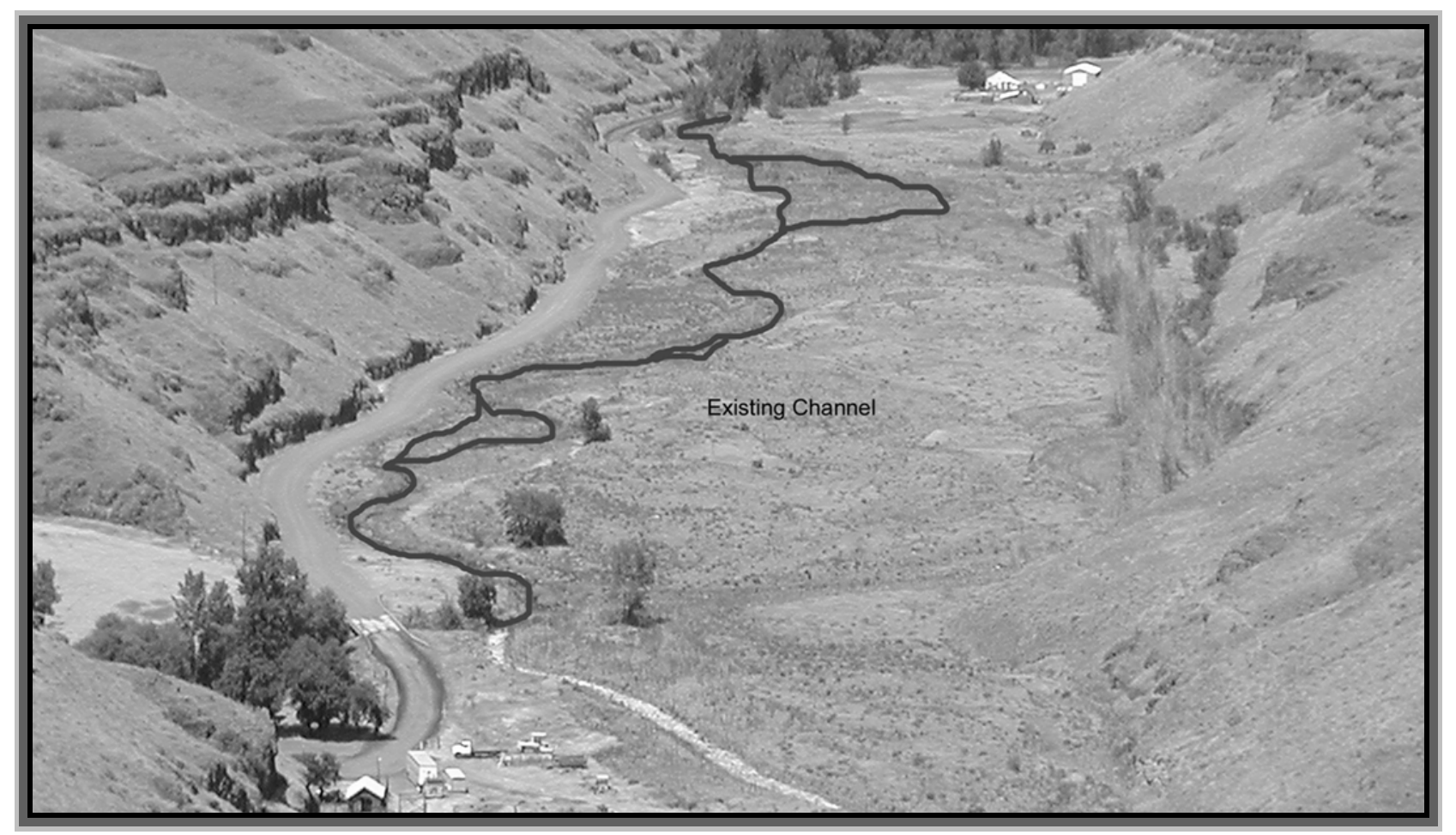

Figure 5. George Creek project site.

Habitat alteration work was to begin soon after surveys were done. However, delays in obtaining materials, and restrictive work windows when the work could be completed without adversely affecting listed salmonids halted completion of some projects. Only the sites on Charley Creek were completed in 2001. Measurements from the other sites will be kept until construction is completed.

Overall, many of the habitat project sites in the Asotin Creek basin were devoid of pools, LOD, and lacked instream variation. Pools were lacking in all three Charley Creek sites, with one site having no pools (Tables 4 and 5). Site complexity, as determined by the variation in thalweg depth, is low in all the pre-project sites except Hendrickson. No LOD was found in any of the Charley Creek sites or in George Creek. With the exception of the Hendrickson site, LOD was lacking in the mainstem sites as well. Project structures should greatly improve overall habitat conditions in the future, and will likely protect the existing road on Charley Creek. Stream length will be increased in the George Creek and Hendrickson project sites. It is likely that the greatest benefit in Charley Creek and Thiessen project sites will come from changes in land management practices, which will promote long term stream habitat recovery. 
Table 4. Summary of pre-construction habitat measurements in three Charley Creek sites, and two mainstem Asotin Creek sites in 2001.

\begin{tabular}{|c|c|c|c|c|c|c|}
\hline Measurement & $\begin{array}{l}\text { Charley } \\
\text { Creek } \\
\# 1-01\end{array}$ & $\begin{array}{l}\text { Charley } \\
\text { Creek } \\
\# 2-01\end{array}$ & $\begin{array}{l}\text { Charley } \\
\text { Creek } \\
\# 3-01\end{array}$ & $\begin{array}{c}\text { Hendrickson } \\
\# 1-01\end{array}$ & $\begin{array}{c}\text { Thiessen } \\
\# 1-01\end{array}$ & $\begin{array}{c}\text { George Creek } \\
\# 1-01\end{array}$ \\
\hline Site length (m) & 28.0 & 48.0 & 27.0 & 170.0 & 150.0 & 1270.0 \\
\hline Mean wetted width (m) & 3.3 & 3.5 & $\begin{array}{r}3.4 \\
12.8\end{array}$ & 9.3 & 14.1 & \\
\hline $\begin{array}{l}\text { Mean depth }(\mathrm{cm}) \\
\text { St.Dev, thalweg }(\mathrm{cm})\end{array}$ & $\begin{array}{l}14.4 \\
24.8\end{array}-1$ & $\begin{array}{l}14.3 \\
22.4\end{array}$ & $\begin{array}{l}12.8 \\
19.0\end{array}$ & 47.3 & $\begin{array}{l}15.6 \\
39.5\end{array}$ & $\begin{array}{r}9.9 \\
14.8\end{array}$ \\
\hline Wetted surface area $\left(\mathrm{m}^{2}\right)$ & 91.6 & 167.3 & 91.4 & 1578.6 & 2121.4 & 6386.3 \\
\hline Wetted volume $\left(\mathrm{m}^{3}\right)$ & 13.2 & 23.9 & 11.7 & 399.7 & 33.0 & 636.2 \\
\hline Width : Depth ratio & 22.7 & 24.4 & 26.5 & 36.7 & 90.4 & 50.5 \\
\hline Number of LOD & 0.0 & 0.0 & 0.0 & 10 & 2.0 & 0.0 \\
\hline LOD area $\left(\mathrm{m}^{2}\right)$ & 0.0 & 0.0 & 0.0 & 21.1 & 4.6 & 0.0 \\
\hline$\%$ LOD area & 0.0 & 0.0 & 0.0 & 1.3 & 0.2 & 0.0 \\
\hline Number of pools & 5.0 & 6.0 & 0.0 & 12 & 34 & 59.0 \\
\hline Mean pool depth $(\mathrm{cm})$ & 18.8 & 20.0 & 0.0 & 39.6 & 26.6 & 21.6 \\
\hline Pool area $\left(\mathrm{m}^{2}\right)$ & 0.8 & 1.4 & 0.0 & 22.7 & 46.0 & 104.1 \\
\hline$\%$ pool area & 0.9 & 0.8 & 0.0 & 1.4 & 2.2 & 1.6 \\
\hline Pool volume $\left(\mathrm{m}^{3}\right)$ & 0.2 & 0.3 & 0.0 & 13.5 & 13.5 & 32.7 \\
\hline & & 1.2 & 0.0 & 3.4 & 4.1 & 5.1 \\
\hline ol Rating & 1.2 & 1.2 & 0.0 & 2.1 & 1.1 & 1.0 \\
\hline & 1.0 & $\begin{array}{l}0.9 \\
79\end{array}$ & $\begin{array}{l}0.9 \\
79\end{array}$ & 0.8 & 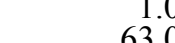 & NA \\
\hline & 7.9 & & 1.9 & 63.0 & & \\
\hline
\end{tabular}

Table 5. Pool classifications at pre-construction in three Charley Creek sites, two mainstem Asotin Creek sites, and one George Creek site in 2001.

\begin{tabular}{|c|c|c|c|c|c|}
\hline Creek Name & & 2001 & Classificati & & \\
\hline Site Name & 1 & 2 & 3 & 4 & 5 \\
\hline Charley Creek & & & & & \\
\hline Charley Creek \#1-01 & 4 & 1 & 0 & 0 & \\
\hline Charley Creek \#2-01 & $\begin{array}{l}5 \\
0\end{array}$ & $\begin{array}{l}1 \\
0\end{array}$ & $\begin{array}{l}0 \\
0\end{array}$ & 0 & 0 \\
\hline $\begin{array}{l}\text { Charley Creek \#3-01 } \\
\text { Total }\end{array}$ & $\frac{0}{9}$ & $\frac{0}{2}$ & $\mathbf{0}$ & 0 & 0 \\
\hline Percent & 81.8 & 18.2 & 0.0 & 0.0 & 0.0 \\
\hline Asotin Creek & & & & & \\
\hline Hendrickson \#1-01 & $\begin{array}{r}4 \\
29\end{array}$ & $\begin{array}{l}3 \\
5\end{array}$ & $\begin{array}{l}5 \\
0\end{array}$ & $\stackrel{0}{0}$ & $\begin{array}{l}0 \\
0\end{array}$ \\
\hline $\begin{array}{l}\text { Thiessen \#1-01 } \\
\text { Total }\end{array}$ & 33 & $\frac{5}{8}$ & $\frac{0}{5}$ & $\frac{0}{0}$ & 0 \\
\hline Percent & 71.7 & 17.4 & 10.9 & 0.0 & 0.0 \\
\hline George Creek & & & & & \\
\hline George Creek \#1-01 & 58 & 1 & 0 & 0 & 0 \\
\hline Total & 58 & 1 & 0 & $\mathbf{0}$ & $\mathbf{0}$ \\
\hline Percent & 98.3 & 1.7 & 0.0 & 0.0 & 0.0 \\
\hline
\end{tabular}

\section{Snorkeling}

In 1999, 2000 and 2001, SRL biologists conducted snorkel surveys to evaluate the utilization of juvenile steelhead between habitat altered (treatment) and index (control) sites in the mainstem of Asotin Creek. Results for each year can be found in Wargo et al. (2000) and Bumgarner and Schuck (2001). All snorkeling in 2001 was conducted on 30 and 31 August. Within each habitat alteration site, single or multiple habitat alteration types (vortex weir, LOD, J-Hook) were snorkeled. Snorkel sites within the altered areas ranged from 5-43 $\mathrm{m}$ in length, with an average of $10.8 \mathrm{~m}$ (Appendix A). Index sites ranged from 35.5-57.5 $\mathrm{m}$ in length, with the average site length of $44.7 \mathrm{~m}$ (Appendix A). 


\section{Index Sites}

Juvenile steelhead (Age 0 and Age 1+) were found in all index sites in mainstem Asotin Creek (Figures 6 and 7), though densities in the lower reaches below George Creek were significantly lower than sites above that point. Overall, mean densities of Age 0 juvenile steelhead in 2001 were lower than was observed in 2000, and slightly higher than in 1999, while densities of Age $1+$ steelhead were higher than the previous two years (Wargo et al. 2000, Bumgarner and Schuck 2001). A number of factors can influence changes in densities, and results presented are merely an indication of relative abundance or desirability of fish to inhabit pool areas, and should not be considered in direct result of the habitat restoration activities described within this report.

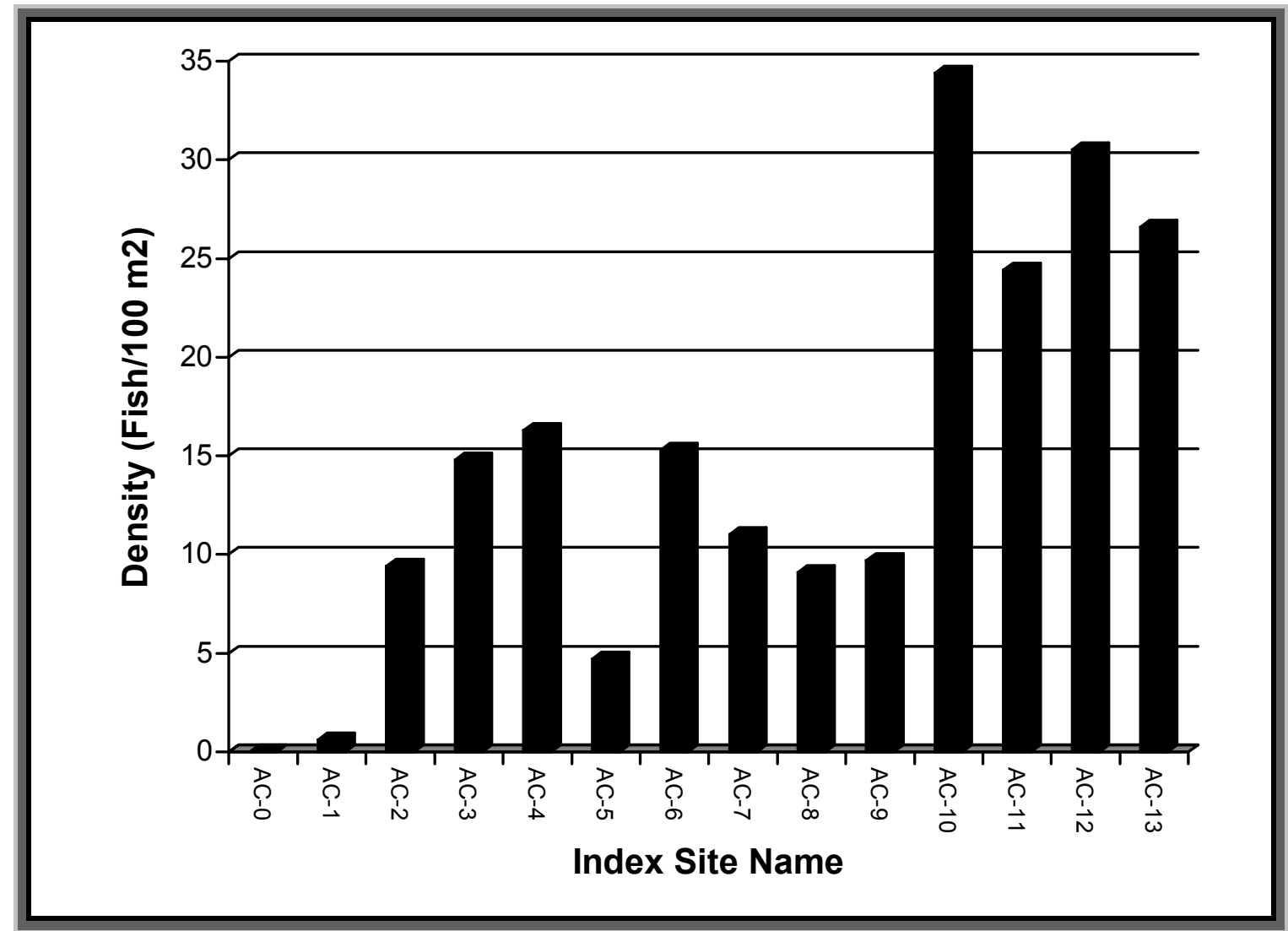

Figure 6. Age 0 juvenile steelhead densities at index sites in mainstem Asotin Creek, 2001. 


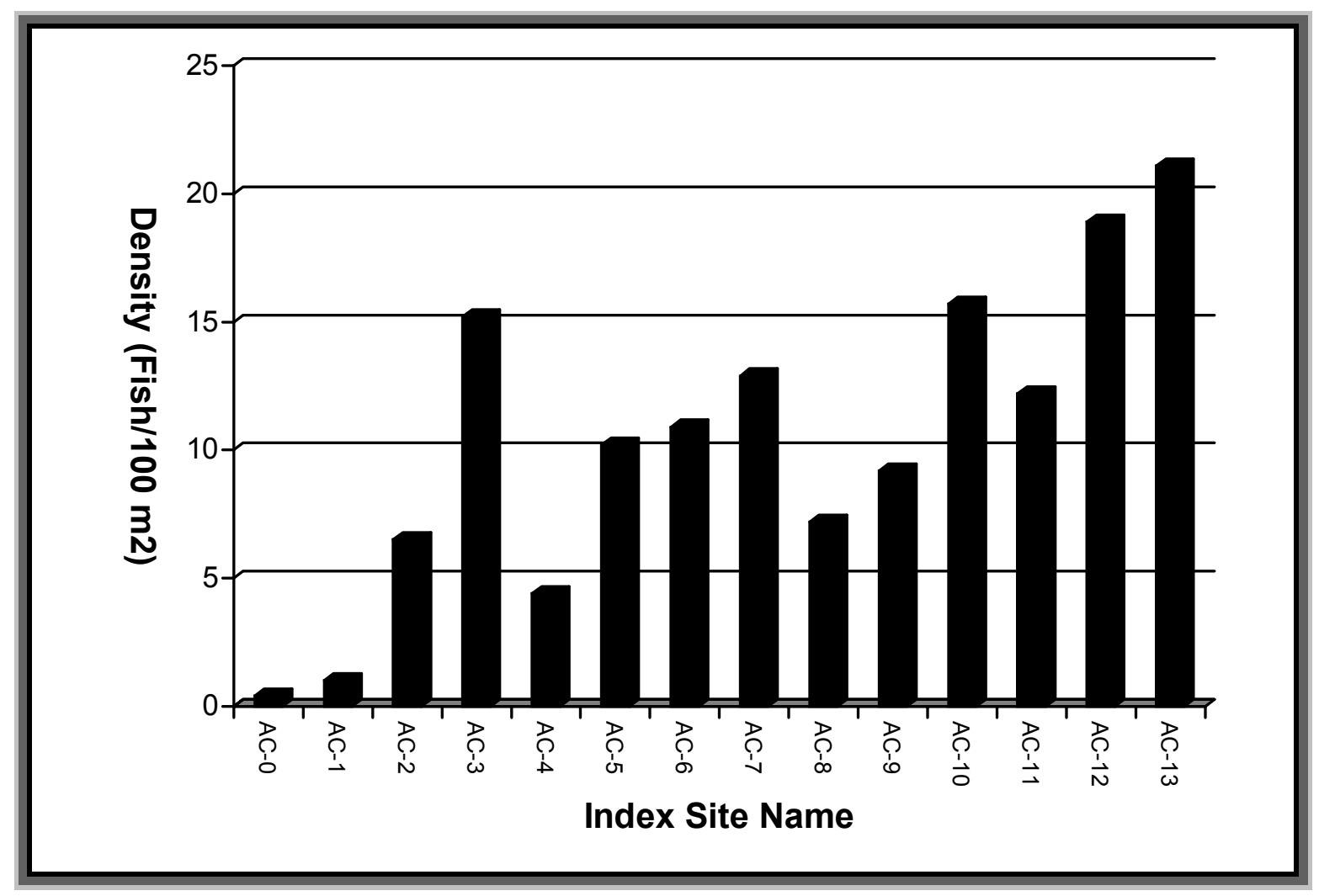

Figure 7. Age 1+ juvenile steelhead densities at index sites in mainstem Asotin Creek, 2001.

\section{Habitat Alteration Sites}

We snorkeled 1998 and 1999 habitat alteration sites that were within the mainstem of Asotin Creek. All treatment sites snorkeled in 2001 were located between Rk 15.1-22.6. Since these habitat sites were located between index sites AC-8 and AC-13, only data from those sites were used for analysis in comparing juvenile densities. Including sites lower in the river could bias the results, as densities within the upper mainstem Asotin Creek are generally higher than densities in the lower eight kilometers.

Between Rk 15.1 and Rk 22.6, there were eight 1998, and one 1999 habitat alteration sites. From those, we snorkeled 38 separate habitat structures (Appendix B), which were considered under three main categories; Vortex, J-Hook, and LOD.

Mean densities of Age 0 and Age 1+ juvenile steelhead in habitat altered sites were significantly greater (Age 0: $t$-test $=3.6, \mathrm{P}<0.001, \mathrm{df}=41$; Age $1+: t$-test $=4.2, \mathrm{P}<0.001, \mathrm{df}=41$ ) than mean densities observed in index sites (Figure 8). 


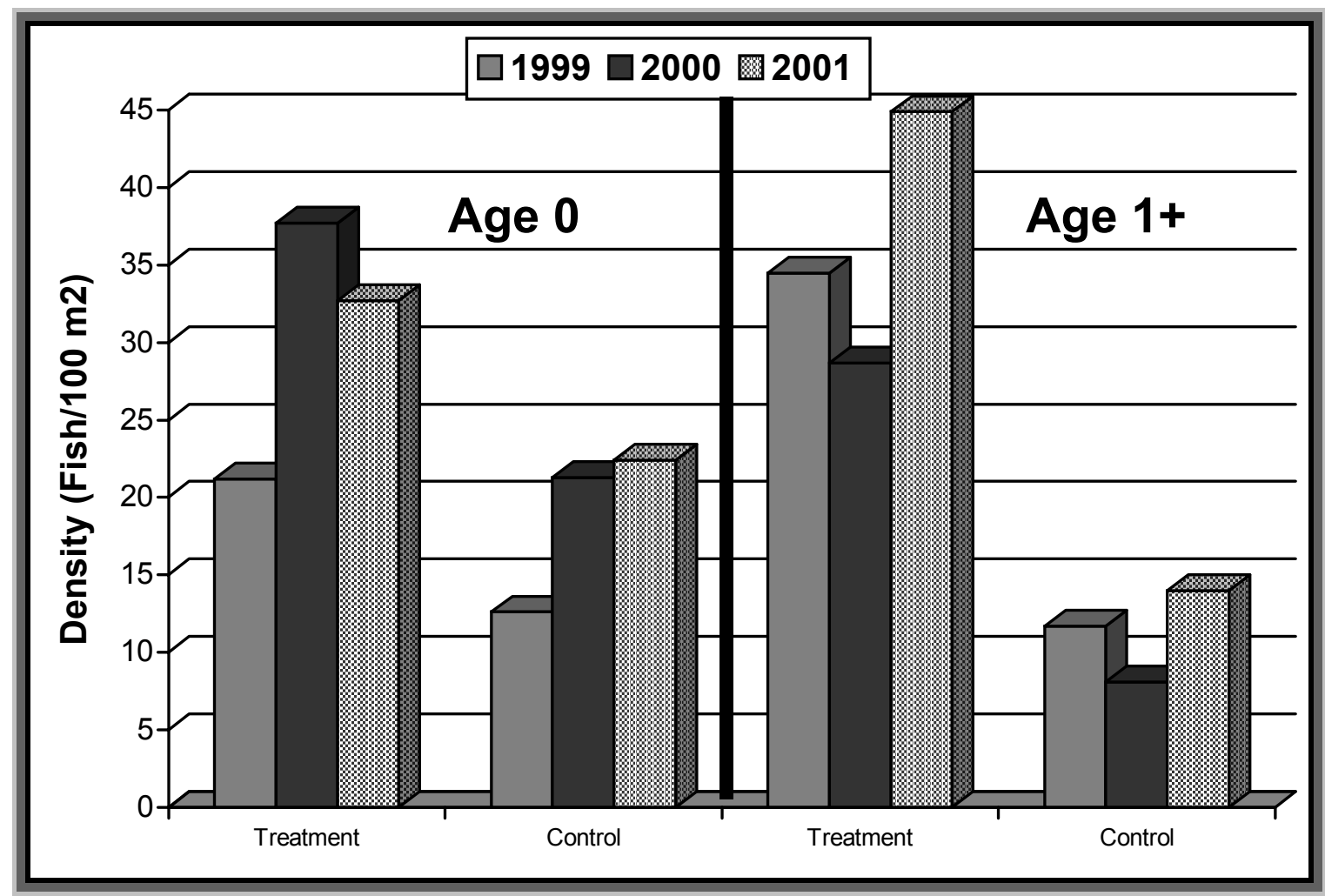

Figure 8. Mean densities of Age 0 and Age 1+ juvenile steelhead at habitat alteration and index sites in mainstem Asotin Creek in 1999, 2000, and 2001.

A one-way ANOVA determined that juvenile steelhead densities within grouped habitat structures (i.e. vortex, LOD, J-hook) were significantly greater in Age 1+ juveniles $(\mathrm{F}=9.7$, $\mathrm{P}<0.001$ ) from the densities within index sites. An ANOVA also found significant difference in densities of Age 0 juveniles $(\mathrm{F}=11.2, \mathrm{P}<0.001)$. Tukey's test was performed on both Age 0 and Age 1+ juvenile data, but was unable to determine significant differences among structure type. This is likely due to the small sample sizes available and large variance observed between individual sites, but of the same structure type. While differences between structure types were not statistically significant, densities within some of the habitat structure types for Age 0 juveniles in 2001 (vortex's) were more than double what was observed in index sites (Figure 9). A similar result was also observed for Age 1+ steelhead in some of the same structure types.

While direct comparisons cannot be made between years, it is interesting to note that certain structures tend to have higher densities than others. Structures that contain higher densities of fish should be considered first when new projects are identified. In addition to summer snorkel surveys, SRL conducted winter night snorkel surveys during February, 2000 and January 2001. Results from the winter snorkel surveys are still preliminary, though they potentially demonstrate a different habitat preference compared to the summer surveys. Winter snorkel surveys will be completed again in 2002, and a more complete analysis will be presented in a future report. 


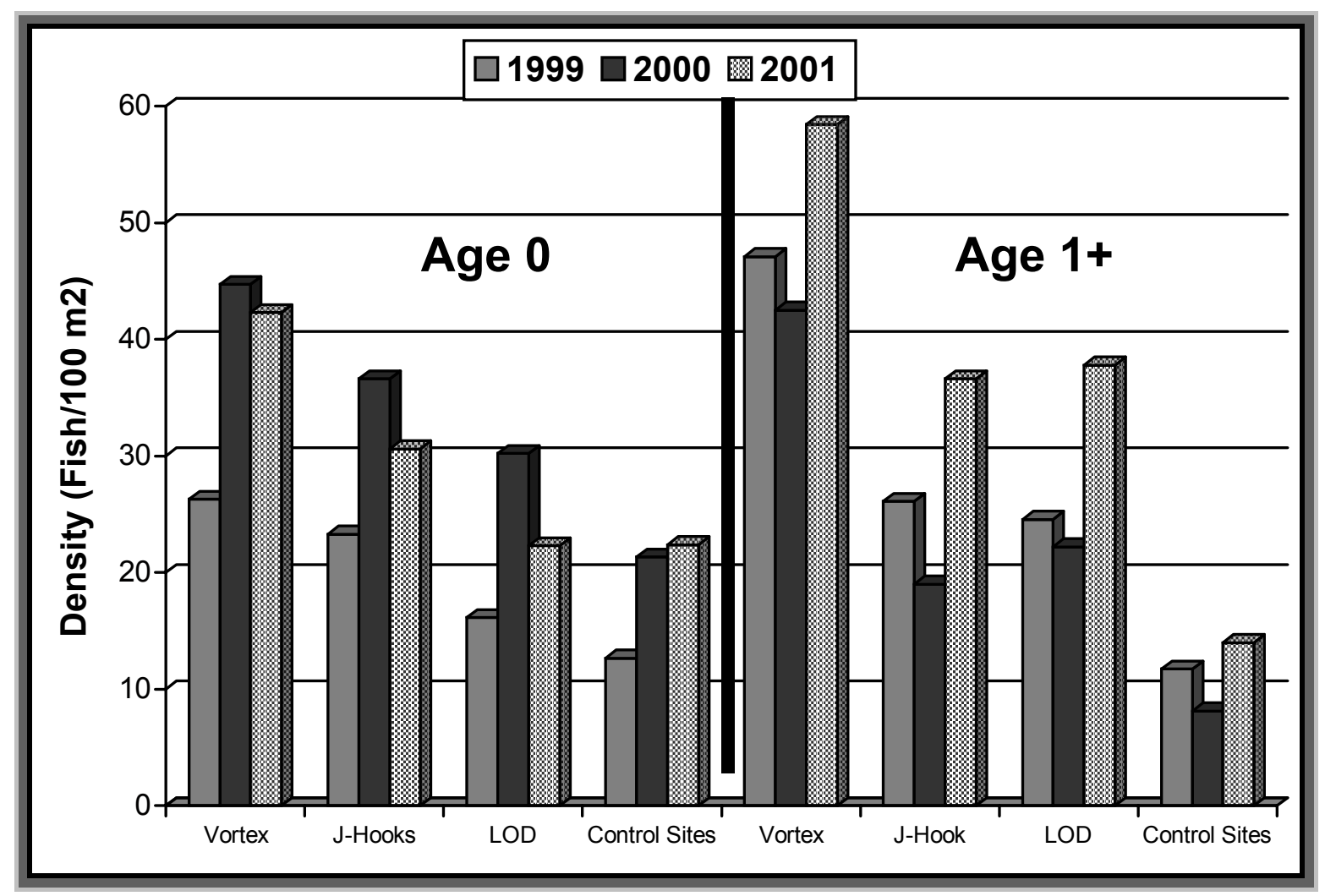

Figure 9. Mean densities of Age 0 and Age 1+ juvenile steelhead in three habitat structure types within habitat alteration and index sites in mainstem Asotin Creek, summers of 1999, 2000, and 2001.

\section{Adult Utilization - Redd Surveys}

Within the spawning ground survey index sections in the mainstem of Asotin Creek, SRL staff counted 151 redds (13.8 redds/river kilometer). Redds that were not associated with instream structures total 119 ( 7.6 redds/kilometer). Redds that were considered to be associated with instream structures totaled 32 (21.2\% of all redds in index sections). Preliminary estimate of the linear distance for all instream structures combined is about 1 river kilometer. Based on that estimate and the number of redds found associated with structures, we conservatively estimate an incidence of 32 redds/river kilometer for altered river reaches, which is substantially higher than redds in unaltered areas.

\section{Temperature Monitoring}

In 2001, ACCD provided the SRL with nine water temperature monitors to document instream temperatures in mainstem Asotin Creek and its tributaries. SRL staff deployed the monitors throughout the basin from 2 May to 25 October (Table 6, Figure 10). Temperatures were recorded every hour. We summarized the data for each day and calculated a daily mean, minimum, and maximum temperature. The warmest temperatures in the Asotin Creek basin occurred in July or August, depending on monitor location. Summary graphs that depict daily mean water temperature, along with minimum and maximum, are provided (Appendix C). 
Actual raw data can be requested through the WDFW Snake River Lab, or ACCD. Additional temperature data were recorded by WDFW Fish Management (Dayton) and the U.S. Forest Service (Pomeroy) at other locations throughout the Asotin Creek watershed (Figure 10).

Table 6. Site location and the greatest daily mean and maximum water temperatures by month at various locations in the Asotin Creek Watershed, 2000 and 2001.

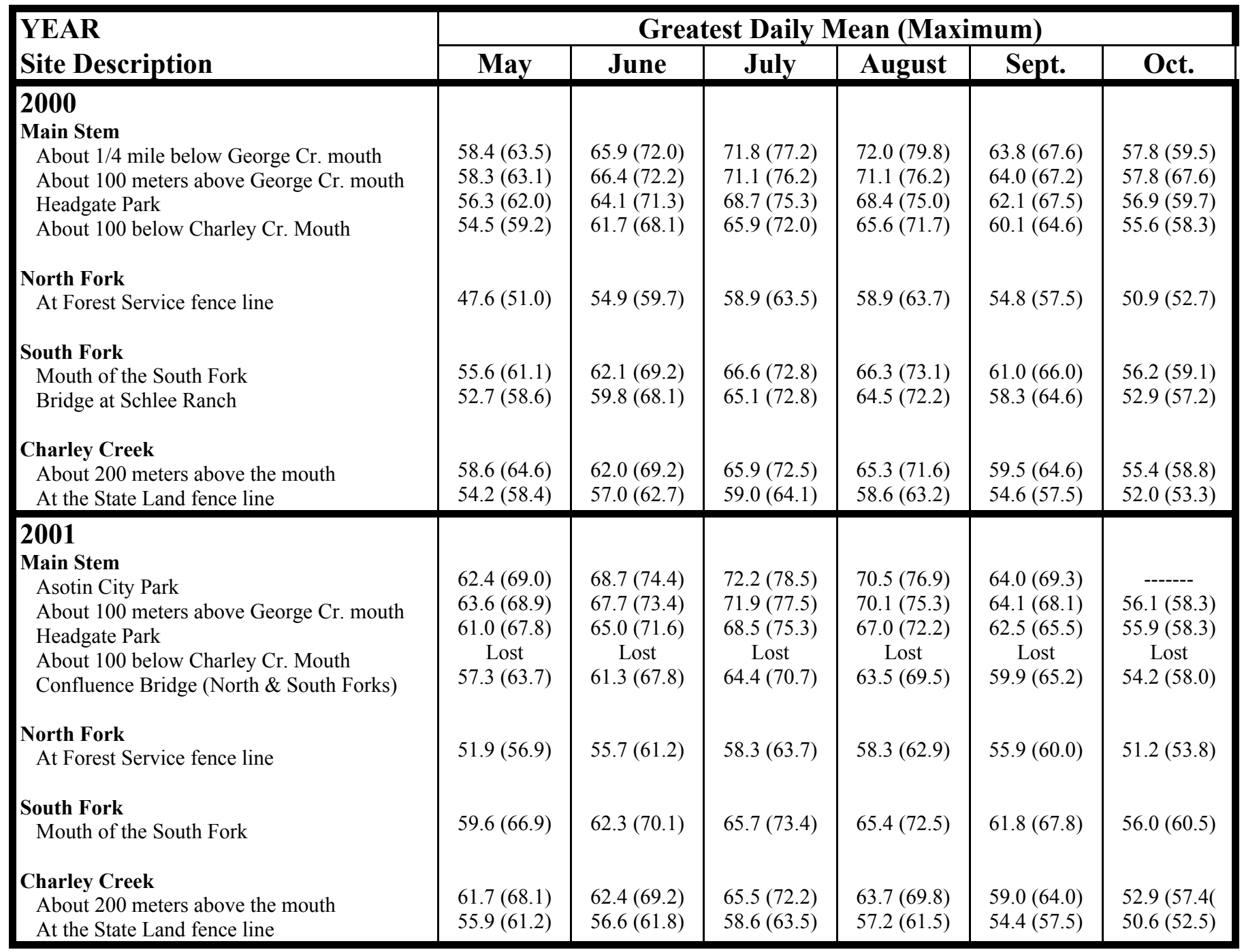




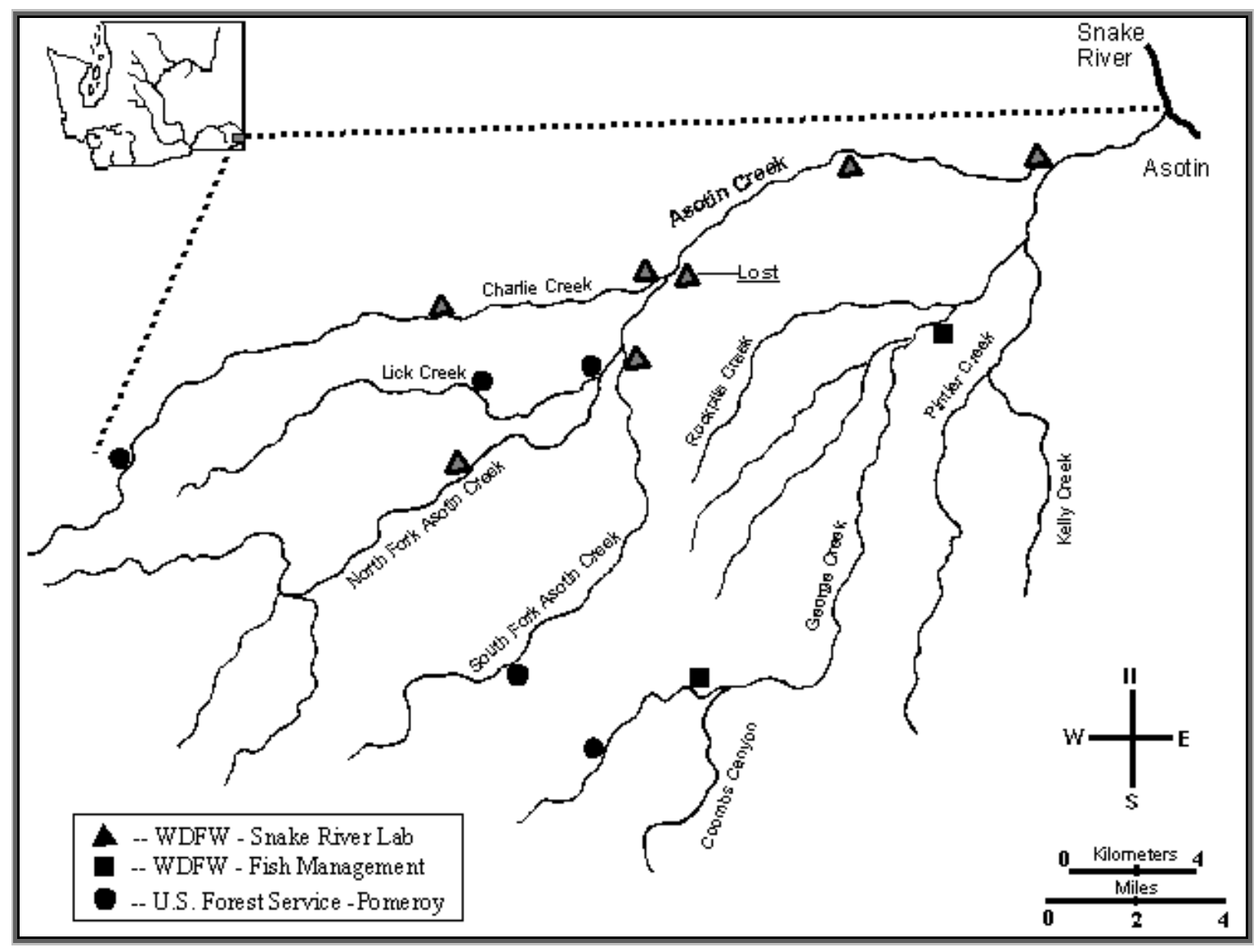

Figure 10. Map of Asotin Creek Watershed and locations of water temperature monitors deployed by WDFW and USFS in 2001. 


\section{Discussion}

\section{Habitat Surveys}

Projects in previous years have generally been directed toward shallow, uniform stream channel sites, which had been damaged by a variety of natural and man caused actions. Generally, large deep pools that provide adult fish habitat have been lacking before being altered. Where deep pools did exist, they were associated with lateral scouring of the channel against unstable banks and lacked complex in-pool structure (LOD, boulders, debris jams, or undercut banks) for fish. These pools provided minimal habitat benefit to juvenile fish because of their poor quality, and only marginal value to adult steelhead. Most non-scour lateral pools were associated with small to medium size boulders in the stream, which created "pockets" of calm water. Sites selected in 2000 and 2001 for habitat work also generally fit this description.

Site selection has usually been driven by two primary purposes; 1) protection of personal property (pastures, houses, etc.), and infra-structure (roads and bridges), with fish friendly habitat engineering techniques, or 2) direct stream enhancement for fish habitat creation (channel reconstruction, riparian enhancement, pool development) with habitat engineering techniques, which may occur concurrently with a Federal or State conservation program (e.g. CREP). Both purposes are valid and represent the Conservation District's attempt to balance multiple goals with a coordinated approach and consolidation of funding sources to accomplish maximum benefit for county residents and for fish.

Habitat restoration projects that were planned between 1998-2001, have included components (rock weirs, j-hooks, and rootwad revetments) to increase fish habitat (i.e. pools and LOD) for both juveniles and adults. In addition, these project components should increase the site complexity overall. LOD and rock weirs in the stream can improve fish habitat by creating large pools which provide juvenile and adult salmon cover from visual disturbance. These structures can also contribute to bank stability which will ultimately increase the quality of habitat within Asotin Creek.

The instream alterations completed in 1998 (see previous reports) and 1999 have increased the number of pools, pool quality and cover, complexity as represented by SD of thalweg depth, and generally reduced water velocity. Habitat alterations did create more complex fish rearing habitat, and will potentially create more long-term fish rearing habitat. Likewise, bank protection goals appear to have been achieved, and it was done in a more "fish friendly" manner than historical attempts at bank protection.

As we have mentioned in previous reports, steelhead populations were shown to increase following similar type projects in Asotin Creek and the Tucannon River in the early 1980's (Viola et al. 1991). These projects could play a key role in stabilizing, restoring, or rebuilding healthy populations of salmonids in the Asotin Creek basin. Long-term monitoring and evaluation of these habitat alteration projects into the future are critical in determining the value of such actions. Beyond these direct benefits, there appears to be an increasing willingness by landowners to work with the management agencies to address habitat problems associated with 
rivers. Attempts to 'control' streams and protect property have historically involved large amounts of rip-rap. Innovative habitat engineering approaches, coupled with landowner willingness to dedicate more room for streams to meander, undoubtedly provide better shortterm conditions for fish. The long-term acceptance of these approaches by the public will depend upon their effectiveness at providing acceptable protection for property.

The nature and extent of pre and post-construction site characterization was limited by available time and funds. Habitat surveys used in this study were designed to be low cost, yet provide a quick, quantitative assessment of habitat variables (depth, pools, LOD) within each site that would allow us to document the changes proposed by the instream projects. These assessments should not be considered a comprehensive analysis of habitat improvement on an ecosystem level but as an indicator of the ACCD's ability to beneficially affect degraded habitat to help recover salmonid populations.

\section{Fish Utilization - Snorkeling and Redd Counts}

Consistent with 1999 and 2000 results, densities of Age 0 and 1+ steelhead were higher in treatment sites compared to control sites. This likely indicates that fish were drawn to the habitat altered sites (pools and cover) from areas of the stream without these elements. Our data show that certain habitat structures appear to be preferred over others, though no specific structure could be determined statistically to hold greater densities than another. Generally, vortex weirs or J-Hooks that create deep pools and/or had LOD associated with the pool were preferred. However, we also documented an increase in the use of some of the LOD structures by Age 0 steelhead compared to the previous year. The reason for this increase is unknown, but we speculate that additional cover (branches or logs) that have been captured by structures may have increased site preference for these small fish. The juvenile steelhead density data obtained from the 1999-2001 snorkel surveys should provide guidance to the type and location of structures to be placed in the future. SRL staff recommends conducting summer snorkeling at the habitat structures for at least two more years to document trends in habitat usage over time. Snorkling at summer index sites will continue on an annual basis to document long-term trends in summer steelhead population within the mainstem of Asotin Creek.

Based on our spawning ground survey results in 2001, it appears that habitat structures placed in Asotin Creek have been beneficial for adult steelhead spawning. Habitat structures have reduced velocities, providing appropriate gravel deposition for construction of redds, and providing places were adults can quickly go for cover to escape predators during spawning. A single habitat type did not appear to be preferred, though more analysis is needed. Attempts will continue to be made for the next few years (stream flows allowing) to document adult utilization of these instream structures compared to un-altered areas.

\section{Temperature}

Summer water temperatures have been identified as a limiting factor to salmonid survival in Asotin Creek (Asotin Model Watershed Plan, 1994). Warm water temperatures result primarily from the loss of riparian vegetation as a result of land use practices land use and natural factors. 
Extensive temperature monitoring throughout the basin was conducted in 2000 and 2001. Overall, mean daily temperatures documented in both years were less than expected, especially near the mouth (highest daily mean temperature recorded was $72{ }^{\circ} \mathrm{F}$ for both 2000 and 2001). Summer water temperatures documented in the Asotin Creek basin by WDFW Snake River Lab in 2000 and 2001 will provide a baseline for future monitoring to document how the riparian area of the creek is improving through re-vegetation planting efforts. SRL staff recommends continuing water temperature monitoring for the next several years to provide an extended database of water temperatures over many different summer conditions. 


\section{References}

Asotin County Conservation District Landowner Steering Committee. 1994. Asotin Creek Model Watershed Plan (Final Draft).

Bumgarner, J., D. Milks, L. Ross, and M. Varney. 1998. Lower Snake River Compensation Plan, Tucannon Spring Chinook Salmon Hatchery Evaluation: 1997 Annual Report to U.S. Fish and Wildlife Service, Cooperative Agreement 14-48-14110-93-J038. Washington Department of Fish And Wildlife, Olympia, Washington. Report \#H98-06.

Bumgarner, J.D., A. E. Viola, and M. L. Schuck. 1999. Asotin Creek: Instream Habitat Alteration Projects - 1998 Habitat Evaluation Surveys. 1998 Progress Report to Asotin County Conservation District.

Bumgarner, J., M. Schuck. 2001. Asotin Creek: Instream Habitat Alteration Projects - 2000 Habitat Evaluation and Snorkel Surveys, and Water Temperature Monitoring. 2000 Progress Report to Asotin County Conservation District.

Everest, F.H. 1986. Abundance, behavior and habitat utilization by coho salmon and steelhead trout in Fish Creek, Oregon, as influenced by habitat enhancement. 1985 Annual Report. Bonneville Power Administration, Division of Fish and Wildlife. Project \#84-11. 100 pages.

Griffith, J. S. 1981. Estimation of the age-frequency distribution of stream-dwelling trout by underwater observation. Progressive Fish Culturist. 43:51-53.

Neilson, R.S. 1950. Survey of the Columbia River and its Tributaries, Part 5. U.S. Fish and Wildlife Service, Scientific Report, No. 38. 41 pages.

Parkhurst, Zell E. 1950. Survey of the Columbia River and it's Tributaries, Part 6. Special Scientific Report Fisheries \#39. USFWS. October.

Platts, W. S., W.F. Megahan, and G. W. Minshall. 1983. Methods for Evaluating Stream Riparian, and Biotic Conditions. General Technical Report INT-138. USDA Intermountain Forest and Range Experiment Station, Ogden, UT.

Schill, D. J., and J. S. Griffith. 1984. Use of underwater observations to estimate cutthroat trout abundance in the Yellowstone River. North American Journal of Fisheries Management. 4:479-487.

Schuck, M.L., A. E. Viola, and J. Dedloff. 1997. Lyons Ferry Trout Evaluation Study 1995-1996 Annual Report to U.S. Fish and Wildlife Service, Cooperative Agreement 14-48-0001-95572. Washington Department of Fish And Wildlife, Olympia, Washington. Report \#H97-08.

Viola, A. E., M. L. Schuck, and S. A. Nostrant. 1991. An evaluation of instream habitat alteration in Southeast Washington, 1983-1989. Washington Department of Wildlife, Report \# F.M. 91-11.

Wargo, L., J. D. Bumgarner, and M. L. Schuck. 2000. Asotin Creek Instream Habitat Alteration Projects: 1999 Habitat Evaluation Surveys. 1999 Progress Report to Asotin County Conservation District. Report \# FPA $00-14$.

Washington Department of Fisheries (WDF), Washington Department of Wildlife (WDW) and Western Washington Treaty Indian Tribes (WWTIT). 1993. 1992 Washington State salmon and steelhead stock inventory (SASSI). 212 pages and 5 regional volumes.

Zar, J. H. 1984. Biostatistical Analysis. Prentice-Hall, Inc., Englewood Cliffs, NJ. 718 pp. 


\section{Appendix A}

\section{Juvenile summer steelhead densities from snorkel surveys at index and habitat sites in 2001}


Appendix A: Table 1. List of index snorkel sites, and juvenile steelhead densities (fish/100 $\mathrm{m}^{2}$ ) in mainstem Asotin Creek, September 2001.

\begin{tabular}{|l|l|l|l|l|l|}
\hline Site Name & $\begin{array}{l}\text { Date } \\
\text { Snorkeled }\end{array}$ & $\begin{array}{l}\text { River } \\
\text { Kilometer }\end{array}$ & $\begin{array}{l}\text { Area } \\
\text { Snorkeled }\left(\mathrm{m}^{2}\right)\end{array}$ & $\begin{array}{l}\text { Age 0 } \\
\text { Density }\end{array}$ & $\begin{array}{l}\text { Age 1+ } \\
\text { Density }\end{array}$ \\
\hline AC-0 & $8 / 30$ & 0.5 & 519.4 & 0.00 & 0.39 \\
AC-1 & $8 / 30$ & 2.1 & 515.2 & 0.58 & 0.97 \\
AC-2 & $8 / 30$ & 3.8 & 352.0 & 9.38 & 6.53 \\
AC-3 & $8 / 30$ & 5.8 & 223.2 & 14.78 & 15.2 \\
AC-4 & $8 / 30$ & 7.7 & 318.7 & 16.3 & 4.39 \\
AC-5 & $8 / 30$ & 8.9 & 469.9 & 4.68 & 10.2 \\
AC-6 & $8 / 30$ & 11.0 & 385.3 & 15.31 & 10.90 \\
AC-7 & $8 / 30$ & 13.2 & 464.0 & 10.99 & 12.93 \\
AC-8 & $8 / 30$ & 14.9 & 418.7 & 9.07 & 7.17 \\
AC-9 & $8 / 30$ & 16.2 & 381.7 & 9.69 & 9.17 \\
AC-10 & $8 / 30$ & 18.6 & 273.3 & 34.39 & 15.73 \\
AC-11 & $8 / 30$ & 19.8 & 303.8 & 24.36 & 12.18 \\
AC-12 & $8 / 31$ & 21.5 & 259.2 & 30.48 & 18.91 \\
AC-13 & $8 / 30$ & 23.0 & 289.6 & 26.59 & 21.06 \\
\hline
\end{tabular}

Asotin Creek Mouth $=$ Rkm 0.0

George Creek Mouth $=$ Rkm 5.2

Headgate County Park $=$ Rkm 13.2

Charley Creek Mouth $=$ Rkm 19.3

North and South Fork Confluence $=23.5$ 
Appendix A: Table 2. List of habitat alteration sites, and juvenile steelhead densities (fish/100 $\mathrm{m}^{2}$ ) in mainstem Asotin Creek, September 2001.

\begin{tabular}{|c|c|c|c|c|c|c|}
\hline Site Name & $\begin{array}{l}\text { Date } \\
\text { Snorkeled }\end{array}$ & $\begin{array}{l}\text { River } \\
\text { Kilometer }\end{array}$ & Habitat Structure & $\begin{array}{l}\text { Area }\left(\mathrm{m}^{2}\right) \\
\text { Snorkeled }\end{array}$ & $\begin{array}{l}\text { Age } 0 \\
\text { Density }\end{array}$ & $\begin{array}{l}\text { Age 1+ } \\
\text { Density }\end{array}$ \\
\hline J. Koch \#11 & $8 / 31$ & 15.1 & Vortex & 155.0 & 30.43 & 17.39 \\
\hline Thiessen \#5 & $8 / 31$ & 17.0 & LOD & 194.9 & 12.82 & 13.85 \\
\hline Thiessen \#5 & $8 / 31$ & 17.0 & LOD & 72.5 & 24.83 & 48.28 \\
\hline Thiessen \#5 & $8 / 31$ & 17.0 & LOD & 55.4 & 34.27 & 37.88 \\
\hline Thiessen \#10 & $8 / 31$ & 17.5 & J-Hook & 26.5 & 33.93 & 37.71 \\
\hline Thiessen \#10 & $8 / 31$ & 17.5 & J-Hook & 32.6 & 61.44 & 18.43 \\
\hline Thiessen \#10 & $8 / 31$ & 17.5 & J-Hook & 35.2 & 51.17 & 73.92 \\
\hline Thiessen \#10 & $8 / 31$ & 17.5 & Vortex & 52.3 & 68.89 & 151.19 \\
\hline Thiessen \#9 & $8 / 31$ & 17.7 & J-Hook & 59.8 & 21.72 & 43.44 \\
\hline Thiessen \#9 & $8 / 31$ & 17.7 & J-Hook & 38.7 & 28.38 & 23.22 \\
\hline Thiessen \#9 & $8 / 31$ & 17.7 & J-Hook & 87.5 & 10.28 & 40.00 \\
\hline Thiessen \#9 & $8 / 31$ & 17.7 & LOD & 85.9 & 19.79 & 25.62 \\
\hline Thiessen \#9 & $8 / 31$ & 17.7 & Vortex & 49.7 & 24.14 & 42.25 \\
\hline Hood \#8 & $8 / 31$ & 19.3 & J-Hook & 68.4 & 14.61 & 42.39 \\
\hline Hood \#8 & $8 / 31$ & 19.3 & Vortex & 52.5 & 19.04 & 15.23 \\
\hline Hood \#8 & $8 / 31$ & 19.3 & Vortex & 52.9 & 18.91 & 22.69 \\
\hline M. Koch \#6 & $8 / 31$ & 20.3 & J-Hook & 37.4 & 26.71 & 32.05 \\
\hline M. Koch \#6 & $8 / 31$ & 20.3 & J-Hook & 39.2 & 17.84 & 48.42 \\
\hline M. Koch \#6 & $8 / 31$ & 20.3 & J-Hook & 47.3 & 16.93 & 27.51 \\
\hline M. Koch \#6 & $8 / 31$ & 20.3 & LOK & 110.0 & 20.90 & 38.17 \\
\hline M. Koch \#6 & $8 / 31$ & 20.3 & Vortex & 40.0 & 39.99 & 67.49 \\
\hline F. Koch \#3 & $8 / 31$ & 21.4 & J-Hook & 57.6 & 43.42 & 27.79 \\
\hline F. Koch \#3 & $8 / 31$ & 21.4 & Vortex & 55.7 & 75.73 & 61.06 \\
\hline F. Koch \#3 & $8 / 31$ & 21.4 & Vortex & 55.4 & 61.32 & 70.34 \\
\hline F. Koch \#2 & $8 / 31$ & 21.9 & LOD & 105.2 & 14.25 & 8.55 \\
\hline F. Koch \#2 & $8 / 31$ & 21.9 & Vortex & 63.2 & 53.76 & 64.83 \\
\hline F. Koch \#2 & $8 / 31$ & 21.9 & Vortex & 48.9 & 67.38 & 98.02 \\
\hline F. Koch \#1 & $8 / 30$ & 22.6 & J-Hook & 74.5 & 16.10 & 13.42 \\
\hline F. Koch \#1 & $8 / 30$ & 22.6 & J-Hook & 60.5 & 16.52 & 16.53 \\
\hline F. Koch \#1 & $8 / 30$ & 22.6 & J-Hook & 41.8 & 69.43 & 67.04 \\
\hline F. Koch \#1 & $8 / 30$ & 22.6 & LOD & 81.0 & 30.86 & 123.45 \\
\hline F. Koch \#1 & $8 / 30$ & 22.6 & LOD & 145.6 & 30.21 & 41.89 \\
\hline F. Koch \#1 & $8 / 30$ & 22.6 & LOD & 70.2 & 11.39 & 9.97 \\
\hline F. Koch \#1 & $8 / 30$ & 22.6 & LOD & 98.2 & 23.42 & 30.56 \\
\hline F. Koch \#1 & $8 / 30$ & 22.6 & Vortex & 34.2 & 23.39 & 40.93 \\
\hline F. Koch \#1 & $8 / 30$ & 22.6 & Vortex & 40.6 & 44.30 & 76.31 \\
\hline F. Koch \#1 & $8 / 30$ & 22.6 & Vortex & 44.7 & 22.37 & 40.27 \\
\hline F. Koch \#1 & $8 / 30$ & 22.6 & Vortex & 43.8 & 43.37 & 50.23 \\
\hline
\end{tabular}




\section{Appendix B}

Average, minimum and maximum water temperatures collected in Mainstem Asotin Creek, North and South Forks of Asotin Creek, and Charley Creek in 2001. 


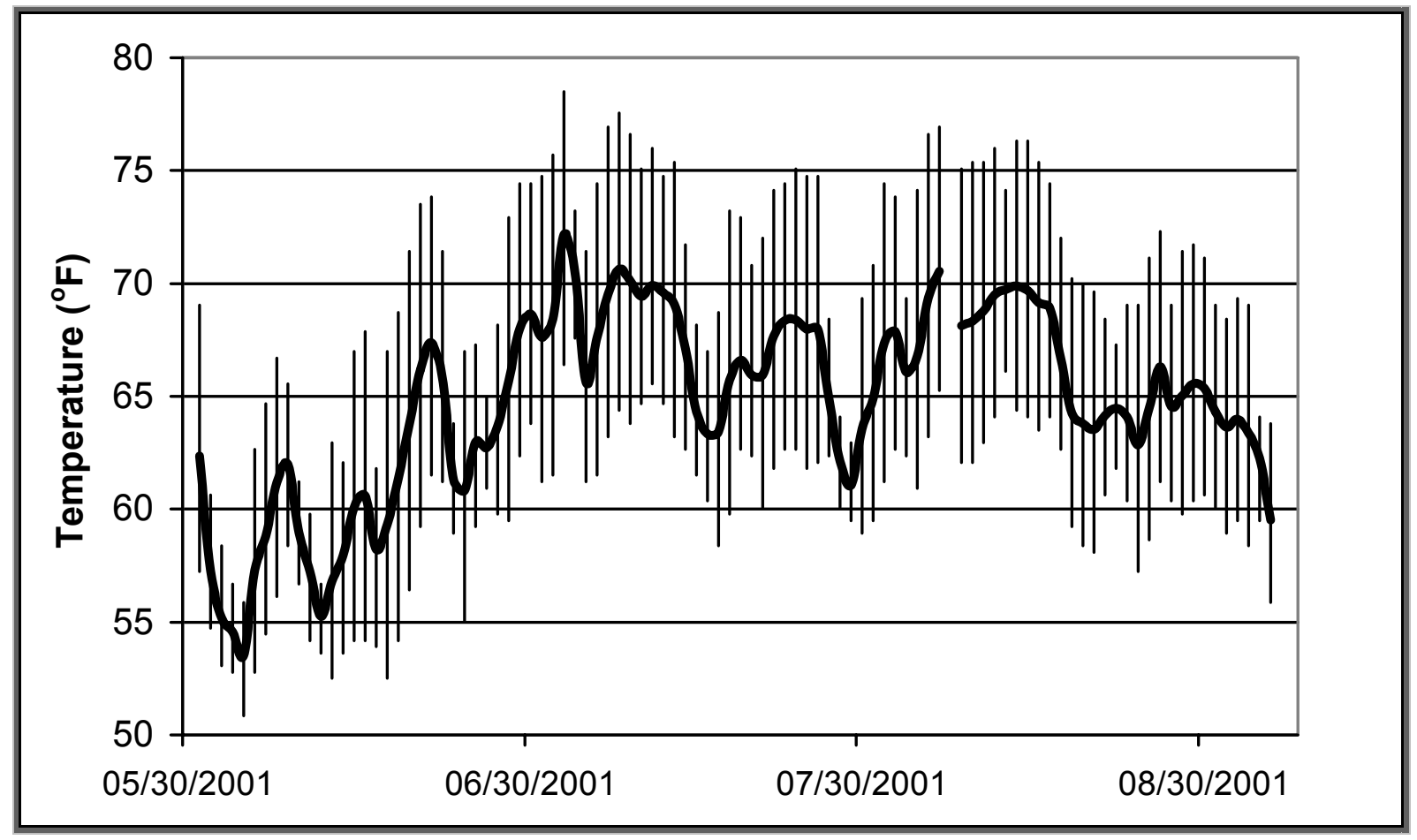

Appendix B: Figure 1. Average, minimum, and maximum water temperature in mainstem Asotin Creek at river kilometer 0.3 in 2001, Asotin City Park.

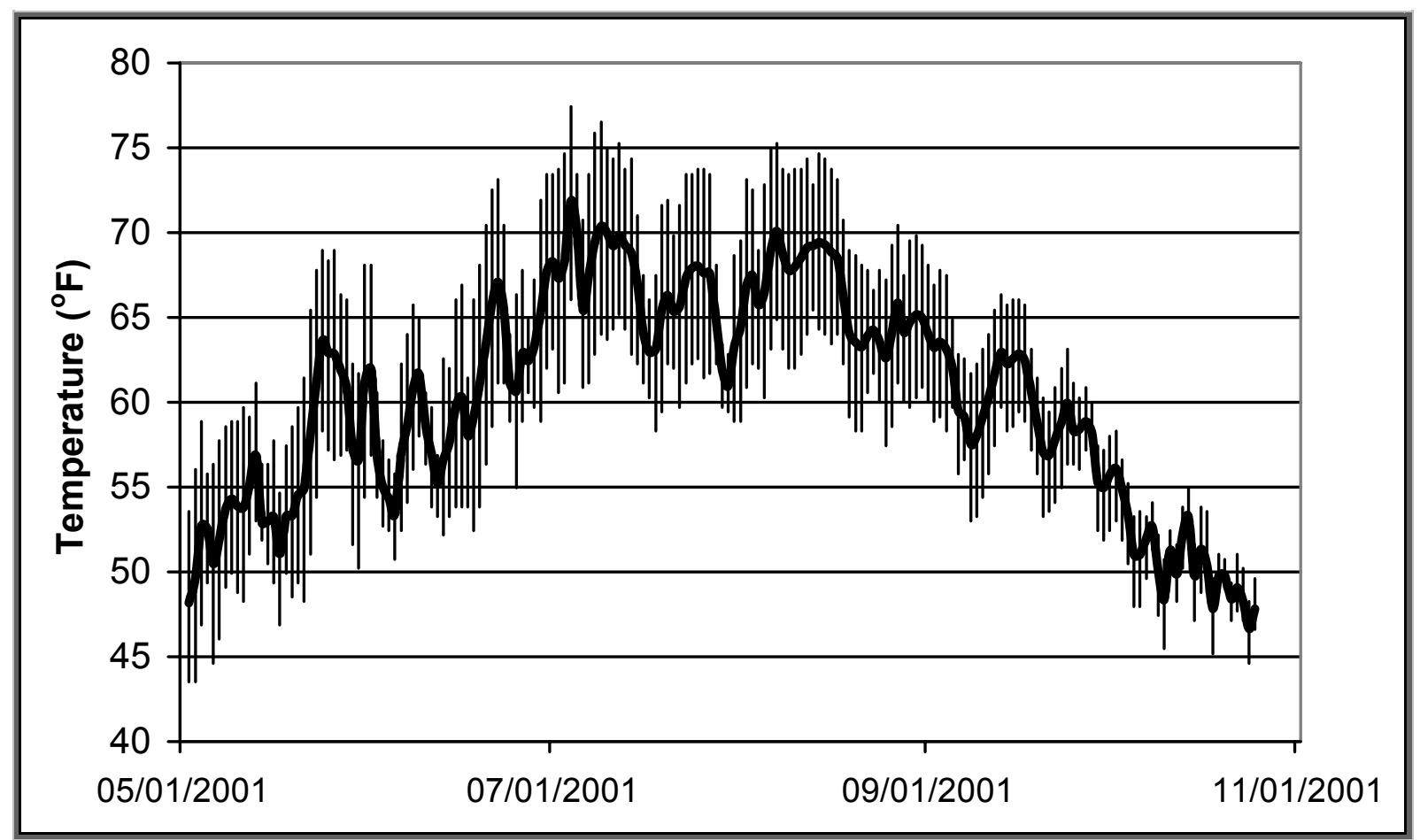

Appendix B: Figure 2. Average, minimum, and maximum water temperature in mainstem Asotin Creek at river kilometer 4.3 in 2001, above where the mouth of George Creek enters the river. 


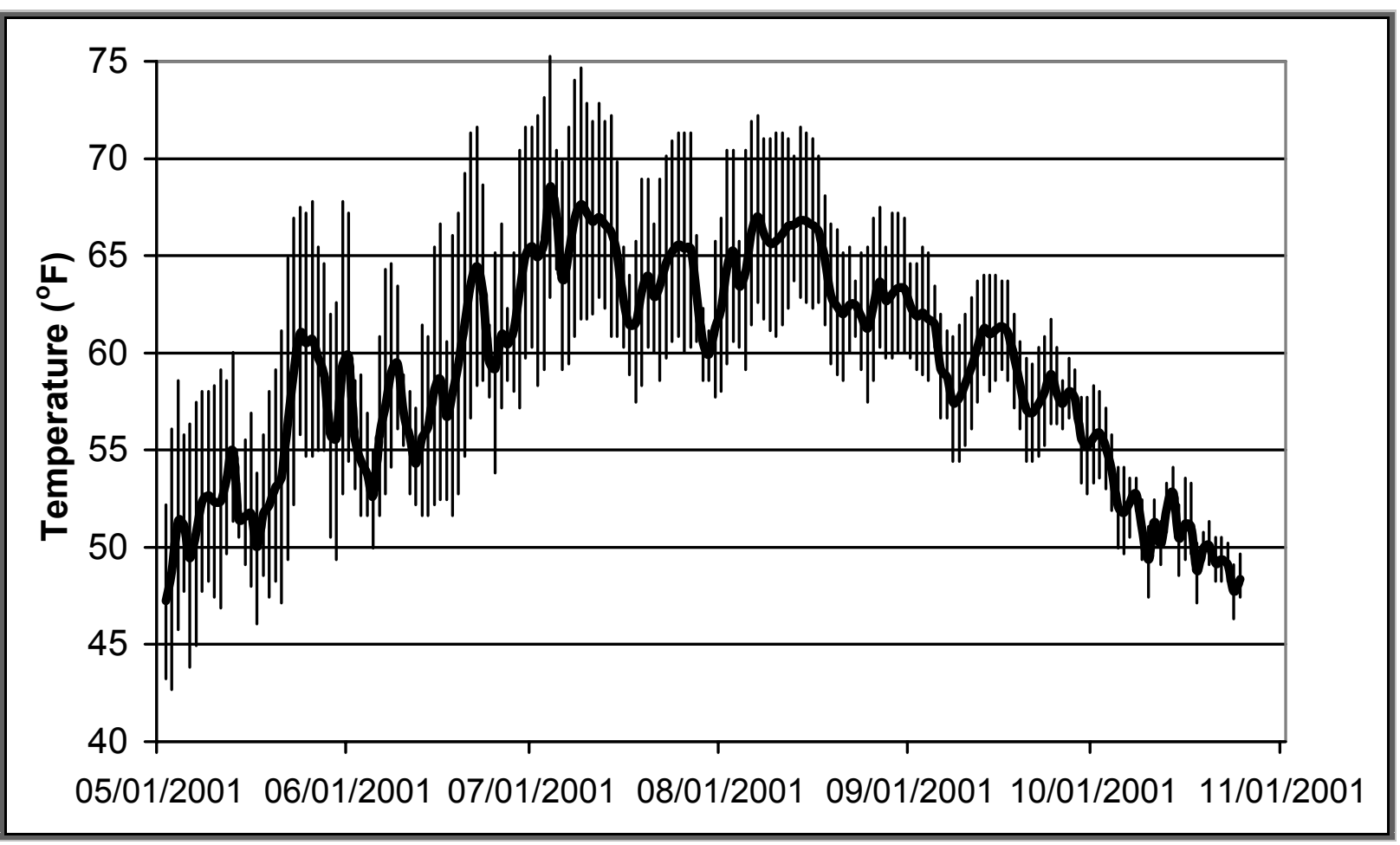

Appendix B: Figure 3. Average, minimum, and maximum water temperature in mainstem Asotin Creek at river kilometer 11.4 in 2001, Headgate County Park.

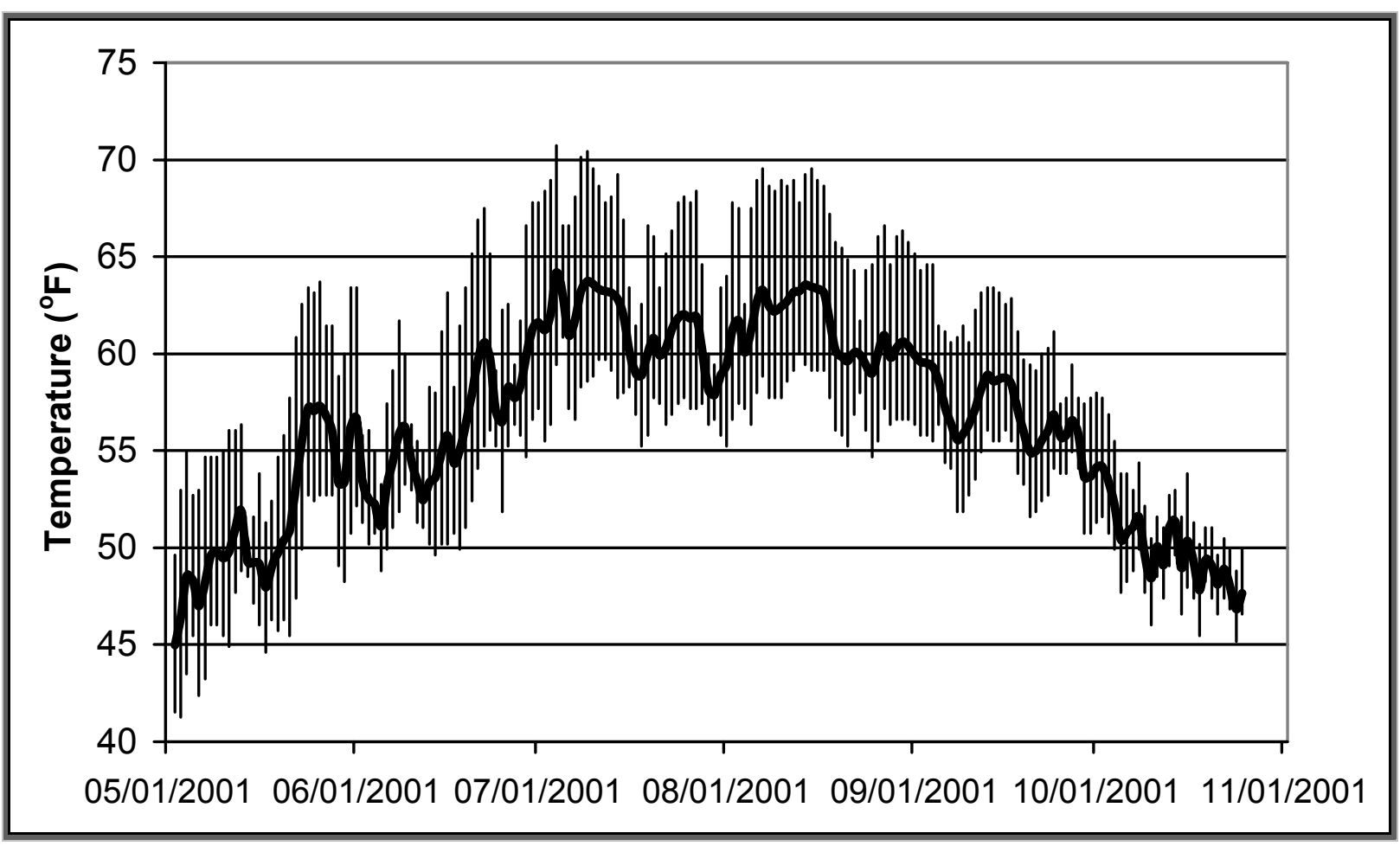

Appendix B: Figure 4. Average, minimum, and maximum water temperature in mainstem Asotin Creek at river kilometer 19.5 in 2001, bridge crossing at confluence of the North and South Forks. 


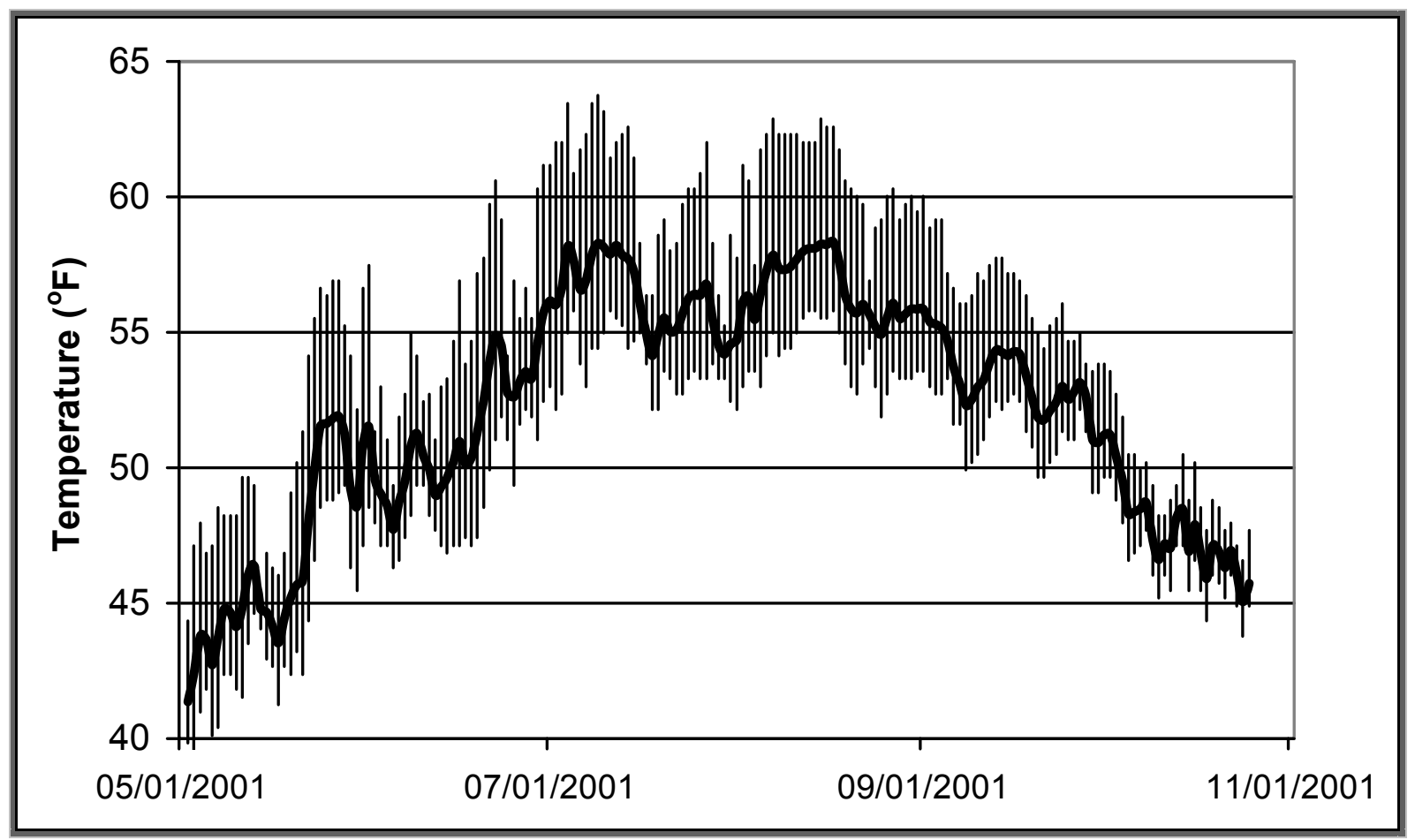

Appendix B: Figure 5. Average, minimum, and maximum water temperature in North Fork Asotin Creek at river kilometer 11.8 in 2001 (U. S. Forest Service boundary fence line).

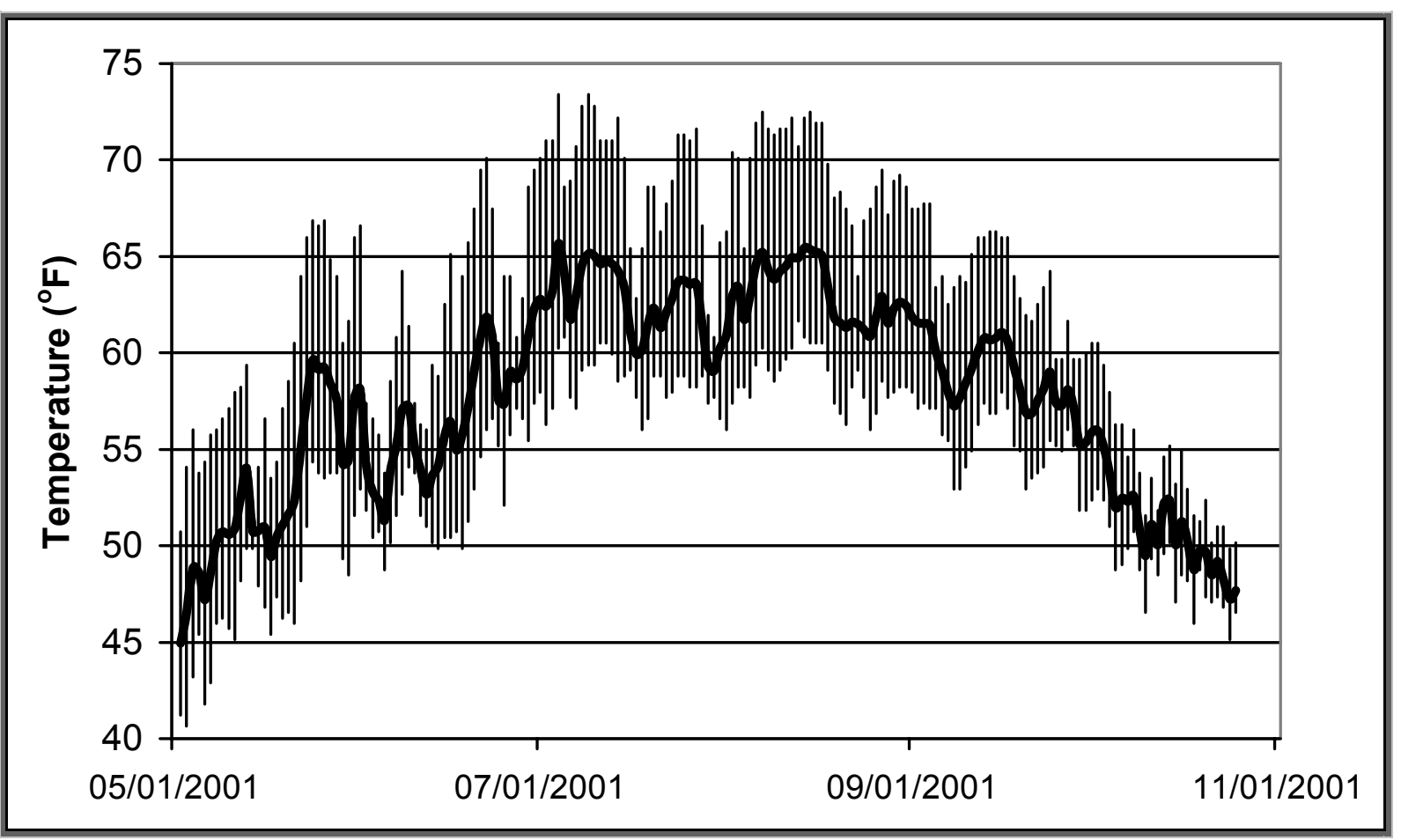

Appendix B: Figure 6. Average, minimum, and maximum water temperature in South Fork Asotin Creek at river kilometer 0.1 in 2001 (near the mouth of the South Fork). 


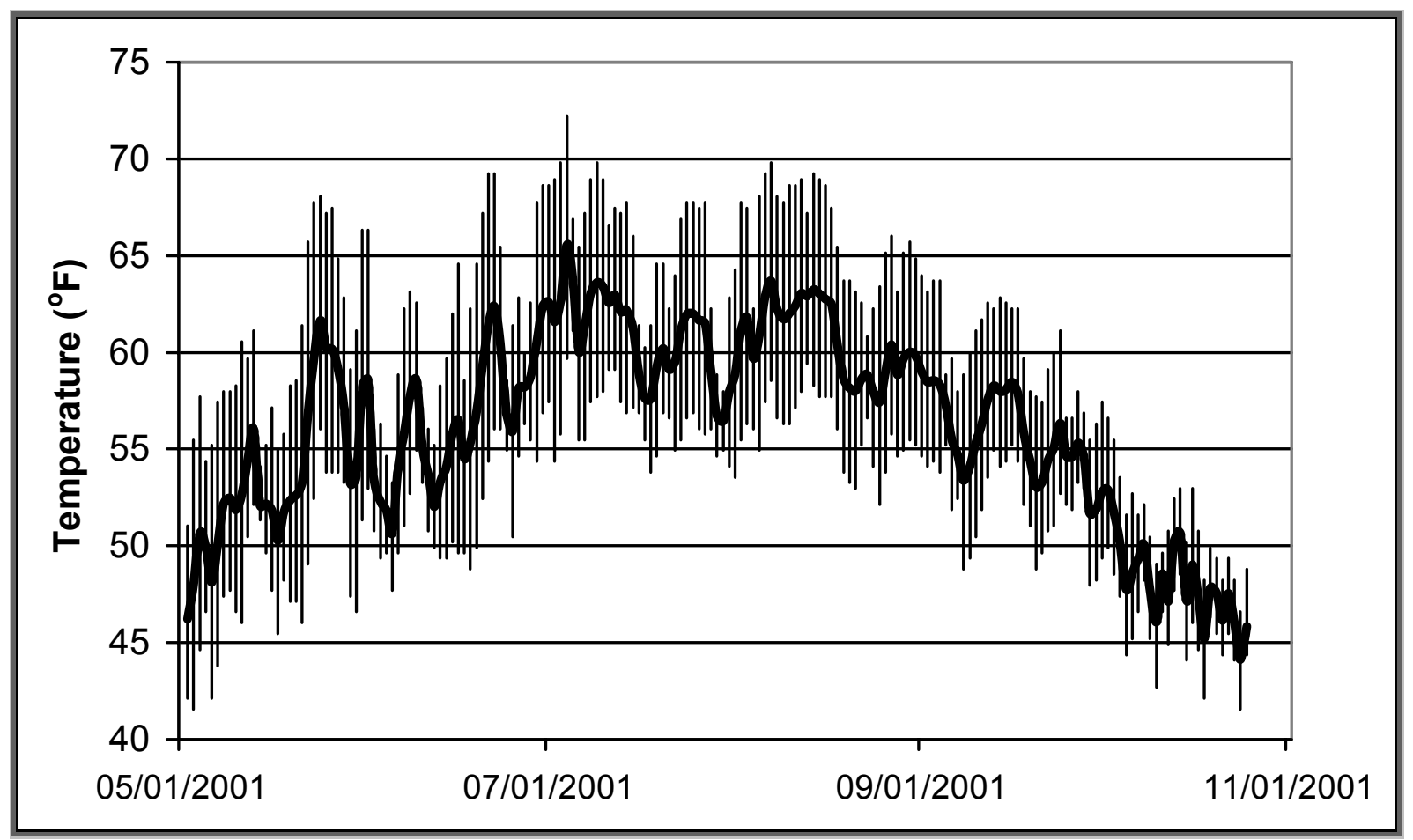

Appendix B: Figure 7. Average, minimum, and maximum water temperature in Charley Creek at river kilometer 0.2 in 2001 (near the mouth of Charley Creek).

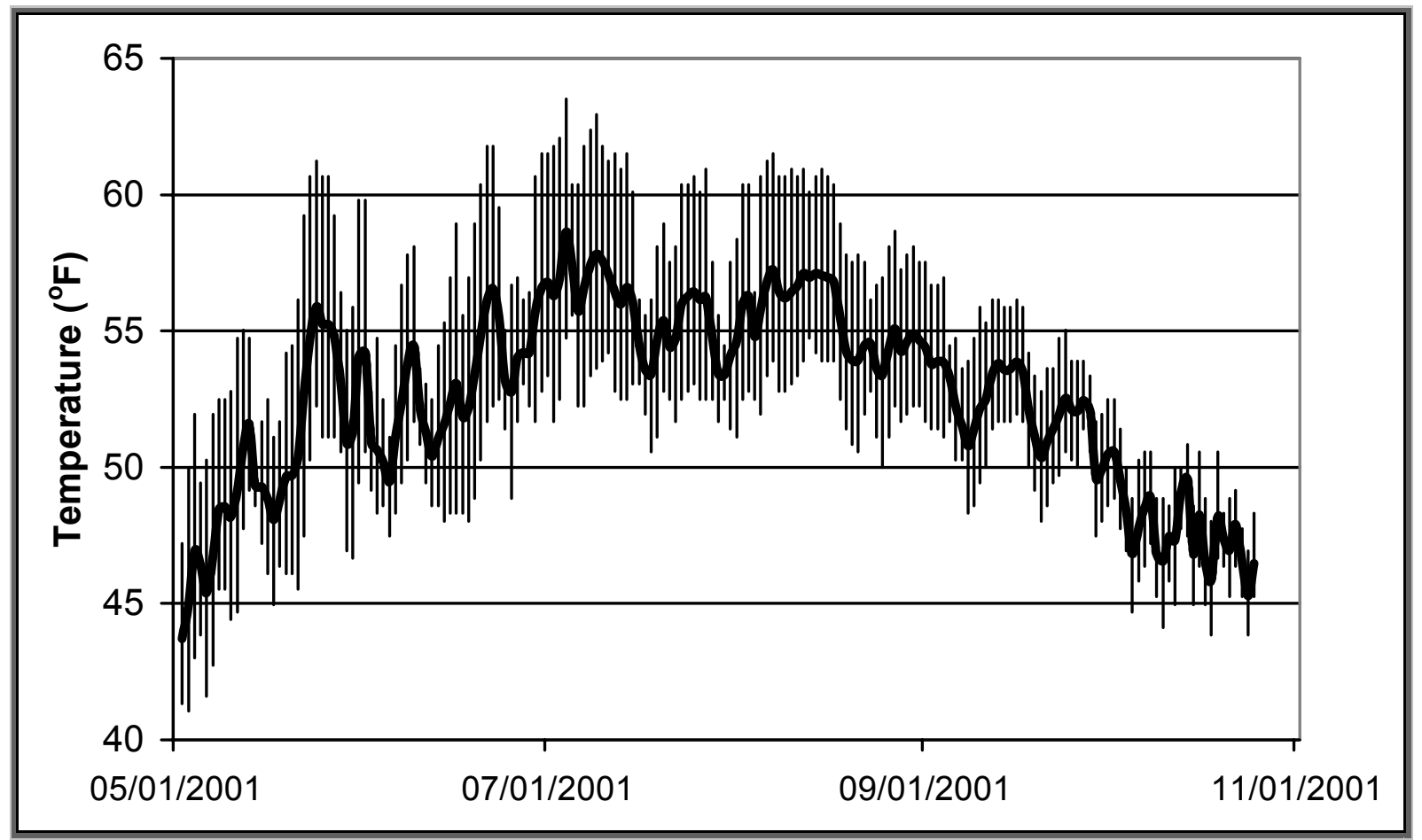

Appendix B: Figure 8. Average, minimum, and maximum water temperature in Charley Creek at river kilometer 8.5 in 2001 (at the boundary fenceline for State land property). 


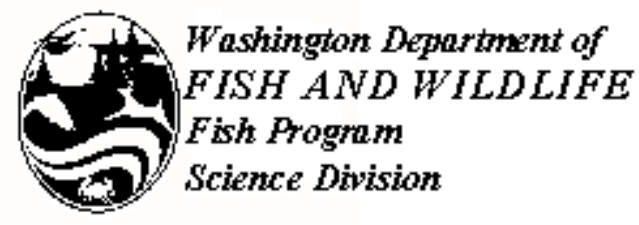

The Washington Department of Fish and Wildlife will provide equal employment opportunities to all potential and existing employees without regard to race, creed, color, sex, sexual orientation, religion, age, marital status, national origin, disability, or Vietnam Era Veteran's Status. The Department is subject to Title VI of the Civil Rights Act of 1964 and Section 504 of the Rehabilitation Act of 1973, which prohibits discrimination on the basis of race, color, national origin or handicap. If you believe you have been discriminated against in any Department program, activity, or facility, or if you want further information about Title VI or Section 504, write to: Office of Equal Opportunity, U.S. Department of Interior, Washington D.C. 20240, or Washington Department of Fish and Wildlife, 600 Capitol Way N., Olympia, WA 98501-1091. 